\title{
Do exit options increase the value for money of public-private partnerships?
}

\author{
Marco Buso ${ }^{1}$ (1) | Cesare Dosi ${ }^{2}$ | Michele Moretto ${ }^{3}$

\begin{abstract}
${ }^{1}$ Department of Economics and Finance, Catholic University of Sacred Heart, Interuniversity Research Centre on Local and Regional Finance (CIFREL), Interuniversity Centre for Public Economics (CRIEP), Milano, Italy

${ }^{2}$ Department of Economics and Management, Interdepartmental Centre "Giorgio Levi Cases" for Energy Economics and Technology and Interuniversity Centre for Public Economics (CRIEP), University of Padova, Padova, Italy

${ }^{3}$ Department of Economics and Management, Interdepartmental Centre “Giorgio Levi Cases” for Energy Economics and Technology, University of Padova, Padova, Italy
\end{abstract}

\section{Correspondence}

Marco Buso, Department of Economics and Finance, Catholic University of Sacred Heart, via Necchi 520123 Milano, Italy.

Email: marco.buso@unicatt.it

\section{Funding information}

Università degli Studi di Padova, Grant/Award Number: BIRD173594

\begin{abstract}
We study the effects of granting an exit option allowing the private party to terminate a Public-Private Partnerships contract early if it turns out to be lossmaking. In a continuous-time setting with hidden information about the private returns on investment, we show that an exit option, acting as a risksharing device, can soften agency problems and, in so doing, spur investment and increase the government's expected payoff, even while taking into account the costs that the public sector will have to meet in the future to resume the project.
\end{abstract}

\section{1 | INTRODUCTION}

Partnerships between private and government entities for the provision of public services are not exclusively a contemporary phenomenon. For instance, examples can be found during the Roman Empire, where postal stations were constructed and managed by private subjects, under contracts, sometimes including maintenance of associated road segments, awarded by municipalities through competitive bidding (PPIAF, 2019). Recent decades, however, have witnessed an increased outsourcing of traditionally public sector activities for several reasons, including the presumed inherent efficiency superiority of private management, the need of leveraging scarce public funds and, sometimes, the attempt "to shift public investment off-budget (and out of public eye)" (Sadka, 2006, p. 20).

Nowadays, the term public-private partnership (PPP) covers a wide range of contractual arrangements, that however share some common features that differentiate them from other forms of cooperation between the public and the private sector. For instance, compared with conventional procurement methods, a distinctive feature of PPPs is that the private party must take a substantial proportion of risk, insofar as they generally involve responsibility over several project functions (e.g., construction, maintenance, and operation of public infrastructures) and remuneration is closely tied to performance (World Bank, 2017).

Tasks bundling and the direct link between rewards and performance can prove beneficial in terms of service quality for end-users and value for money for the taxpayer (Hart, 2003). However, the long duration of PPPs, needed to 
attract private funding and secure investment, can lead to several problems due to changing circumstances that may occur throughout the partnership term (Saussier \& de Brux, 2018). For instance, "contracts [can] suffer from being signed in contexts with pervasive uncertainty over future demands and costs" (Iossa \& Martimort, 2015, p. 8), and around the world there are several examples of PPPs which have encountered problems because of unrealistic demand expectations, cost inflation, changes in user preferences or changes in policies affecting the use of the facilities (Engel et al., 2014). Since public authorities generally retain the ultimate responsibility for service delivery (Forrer et al., 2010; Yang \& Zhang, 2010), governments have often been forced to undertake costly renegotiations or simply to resume operations (Guash, 2014; Zhang \& Xiong, 2015).

Based on these pieces of evidence, scholars and PPP stakeholders have often called for injecting more flexibility in PPP agreements. In other words, contracts should be written so as to anticipate and rapidly react to changing circumstances throughout the term of the partnership (Demirel et al., 2017). Indeed, while in business-to-business relationships parties tend to adapt ad hoc when faced with unexpected circumstances, public contracts, subject to political scrutiny and accountability, require ex-ante specified rules for amendments and adaptations (Beuve et al., 2019). Moreover, while private agreements are often governed by a combination of formal rules and informal incentives, the latter (e.g., the threat of losing future contracts due to opportunistic behavior) tend to play a relatively minor role in public-to-private relationships (Calzolari \& Spagnolo, 2009; Kelman, 1990, 2002).

In PPP contracts, adaptation provisions can take on several forms, including, for instance, minimum revenue, minimum income or loan guarantees (see, e.g., Adkins \& Paxson, 2017; Cruz \& Marques, 2013; Iossa et al., 2007; Jin et al., 2019; Takashima et al., 2010). However, while presumably increasing the chances of attracting private capital, these mechanisms can impose uncertain public costs (World Bank, 2019) and, perhaps even more importantly, require continuous and precise monitoring and assessment of project performance, to avoid opportunistic behavior by private partners and unjustified escalations of public costs.

Another flexibility provision, which we will focus on in this paper, is allowing the private partner to terminate the service agreement early. ${ }^{1}$ As a matter of fact, even though the right to abandon a loss-making activity is rarely spelled out in PPP agreements, ${ }^{2}$ termination options are often embedded within contracts in the form of penalties for early exit, which can be viewed as the price to be paid to breach the agreement (Scott \& Triantis, 2004). In other words, a contractual penalty clause can be economically interpreted as the "strike price" of a put option. As long as the price is not higher than the cost of continuing to supply the service, introducing a termination fee is de facto equivalent to granting an exit option having a positive private value. Hovever, that value is often not fully acknowledged by contracting authorities.

Our main objective is to examine whether the (explicit or implicit) granting of an exit option can increase the government's payoff with respect to "lock-in" contracts. For this purpose, we develop a model where a private-sector company is entrusted with the responsibility for building and operating an infrastructure project of public interest, in exchange of a lump-sum contribution to investment costs and the right to collect end-user charges. Moreover, the government's offer also includes an exit option, which can be exercised at any time by paying an early termination fee fixed upon contract award. ${ }^{3}$ Finally, we assume that, in the event of exit by the company, the government, acting as a provider of last resort, will resume the project by taking direct responsibility on service provision.

The model is developed in continuous time, by incorporating into a real options framework a principal-agent problem where the company holds private information on operating profits evolving stochastically over time. In so doing, we intend to restrict our attention on situations where regulators, being unable to implement state-contingent risk-sharing provisions, have to resort on stationary incentives. Moreover, unlike other papers that address service quality issues in moral hazard models where the project implementation time is treated as an exogenoeus variable, we focus on the timing of implementation. For instance, our model applies to situations where the project's functional and technical features are sufficiently well-defined and verifiable, and the government's primary objective is to accelerate investment at the lowest possible public cost. In this context, the company's "effort" essentially consists of reducing the time delay before committing a capital outlay.

Our main result is that the blending of direct subsidies and exit options can soften agency problems and, in so doing, provide a higher value for money to the government. The rough logic for this result is as follows. When returns are uncertain, companies tend to delay investment to learn more about future profits. The public grant serves the purpose of lowering the capital commitment by the firm and, thus, accelerating project implementation. However, under private information about the revenue potential, the government needs to pay information rents to bridge the gap between the privately and the publicly optimal timing of investment. Specifically, since companies with low-revenue potential are willing to wait longer (for a higher revenue state before investing), the government needs to limit the rents 
that have to be paid to high-revenue potential companies to induce them to reveal themselves truthfully. Our main result is that an exit option can limit the differentiating value of delay and rents left to the private party, thus inducing more efficient investment thresholds at a lower public cost.

The remainder is organized as follows. In Section 2 we position our work within the literature. In Section 3 we present the main assumptions of the model. In Section 4 we describe the impact of the exit option on the project's private value. In Section 5 we derive the optimal mix of front-loaded and option incentives for a revenue-maximizing government, by first solving the case of symmetric information and then turning to the case of private information on the operating profits. Section 6 concludes. The proofs are presented in the appendices.

\section{2 | RELATED LITERATURE}

This paper can be positioned at the intersection of two literatures. The first is the one using principal-agent frameworks to examine how contract design and incentive mechanisms can shape behavior and PPP performance (see, e.g., Auriol \& Picard, 2013; Hart, 2003; Hoppe \& Schmitz, 2013; Iossa \& Martimort, 2015; Martimort \& Pouyet, 2008). Within this literature, relatively few studies, using a dynamic approach, have explored the effects of endogenous (Engel et al., 2001) or state-contingent (Danau \& Vinella, 2017) service duration.

The second body of literature has focused instead on the value of real options embedded into public-private contracts (see, e.g., Alonso-Conde et al., 2007; Blank et al., 2016; Brandao \& Saraiva, 2008; Huang \& Chou, 2006; Martins et al., 2015) without, however, providing much guidance on how to efficiently design option-like incentives.

Some papers have tried to bridge the gap between the two literatures by incorporating into a real option framework a contract design problem. A common feature of these models is the attention paid to the timing of service delivery, which is modeled as a decision variable rather than being taken as exogeneoulsy given. For instance, Takashima et al. (2010) study the interaction between a government and a private firm when they time an investment decision, while Scandizzo and Ventura (2010) consider a concession contract for developing a publicly owned natural resource where the private party is required to pay a price to compensate the government for the loss of amenities.

Broer and Zwart (2013) and Soumare and Lai (2016) depart from these works by introducing asymmetric information. In particular, Broer and Zwart (2013) examine the optimal regulation of an investment undertaken by a monopolist with private information on capital costs, while Soumare and Lai (2016) compare, within a model of hidden information, different forms of public support (loan guarantee vs. direct investment) in PPPs. Di Corato et al. (2018), for their part, study how exit options, resulting from the government's inability to enforce sufficiently strong penalties for breach of contracts, can affect bidding behavior in multidimensional auctions for the provision of long-term environmental services.

Within this mixed literature, our specific contribution is twofold. First, in a PPP setting with private information on the project's cash flows, we derive the optimal government's decision regarding the degree of exit flexibility granted to the contractor. Second, we examine the effects of flexibility upon the timing of investment and the government's overall payoff, by taking into account the potential financial costs deriving from taking charge of the project in the case of termination by the private partner.

Regarding the methodology, we follow the dynamic mechanism design approach developed by Baron and Besanko (1984), Battaglini (2005), Esö and Szentes (2007), Pavan et al. (2014), and others. In particular, we build on the approach suggested by Kruse and Strack $(2015,2019)$ who show, in a continuous-time setting, that an incentive-compatible allocation mechanism can be obtained without continuous monitoring of the state variable. Our specific contribution consists of extending their methodology to the case where, besides direct incentives (cash payments), the government also relies on option-like mechanisms, namely, on an early termination option.

\section{3 | SET UP}

A government entity, such as a city, intends to rely on a private-sector company (henceforth "the firm") for building and operating a public infrastructure facility. The reasons underlying the choice of using a PPP, which is taken here as given, may be linked to financial constraints and/or to the possibility of exploiting the expertize and efficiencies that the private sector can bring to deliver infrastructure services. Besides the benefits realized by direct users, the new facility is expected to provide valuable externalities ("public benefits") to the community administered by the awarding authority 
("the government"). As an example, one may think of a new by-pass, planned to ease gridlocks in a heavily congested urban area and curb local pollution by increased traffic fluidity.

The government intends to maximize the value for money delivered by the PPP. Specifically, in our framework, the government's payoff is defined as the difference between the present value of public benefits and the public funds devoted to the project over its entire life span. ${ }^{4}$ The exclusion of the firm's own profit, which is a common assumption in the PPP literature (see, e.g., Hart, 2003; Iossa \& Martimort, 2015), can be justified, for instance, when the project sponsor is a local government that only cares about the benefits and costs of his own constituents (Martimort \& Pouyet, 2008). ${ }^{5}$

The project, whose technical and functional features are clearly defined and verifiable, requires a sunk investment of $I$ and then a fixed O\&M cost per unit of time (say, per annum) denoted as $c$. For technical convenience, we assume that construction can be instantaneously carried out, that the infrastructure has an infinite life and that, once implemented, the project will provide a perpetuity of annual public nonfinancial benefits, valued at $b$, above and beyond those accruing to direct users. ${ }^{6}$

The government (he) is able to commit at time $t=0$ to a take-it-or-leave-it contract offer to the firm (she), having no outside option, ${ }^{7}$ including the following terms and conditions.

First, the contract gives the firm the responsibility to build the facility and then maintain and operate it all along the contract period which is assumed to be long enough to be approximated as infinite. Second, the contract entitles the firm to receive upon investment a fixed nonrepayable capital grant $0 \leq S \leq I$ and, afterwards, to collect end-user charges. Since the issue of the optimal pricing policy lies beyond the scope of the paper, we simply assume that the firm will be allowed to extract all users' surplus. Finally, the agreement legally binds the firm to pay a fixed sum of money, denoted by $L \geq 0$, in the event of premature abandonment of operation. ${ }^{8}$ Throughout the paper, $L$ will be referred to as the exit (or early termination) fee.

In the case of exit by the firm, the government will insource the project to ensure service continuity. Specifically, we assume that the government will resume the project by incurring the same cash-flows (revenues and O\&M costs) that the firm would have incurred. For instance, as pointed out by Auriol and Picard (2013), this setting fits particularly well when uncertainty comes from the demand size, because "demand conditions are revealed after construction and exploitation of the facility and are readily transferred to the public authorities" (Auriol \& Picard, 2013, p. 196). On the cost side, our assumption can be justified by appealing to the government's ability to narrow the private comparative advantage in service production, which might have motivated the use of a PPP instead of direct public provision. However, in the appendix, we will generalize our results to the case where the government needs to afford additional costs beyond those the firm herself would have incurred absent the termination (see Appendix F).

The project's revenues, ${ }^{9}$ denoted as $x_{t}$, are assumed to evolve stochastically according to the following trendless Geometric Brownian process: ${ }^{10}$

$$
\frac{d x_{t}}{x_{t}}=\sigma d z_{t} \quad x_{0}=x
$$

where $\sigma>0$ is the constant instantaneous volatility and $z_{t} \sim N(0, t)$ is a standard Wiener process having a normal distribution with zero mean and variance $t$. Since the solution of the differential Equation (1) is given by $x_{t}=x \exp \left(-\frac{\sigma^{2}}{2} t+\sigma z_{t}\right)$, the revenues at time $t$ depend on the initial value $x$ and the contemporaneous shock $z_{t}$ at time $t$.

The initial value $x$ can be interpreted as the revenue potential, reflecting the firm's innate ability to seize opportunities coming from the project. While the uncertainty parameter $\sigma$ is assumed to be common knowledge, the firm has private information on $x$ and the future realizations $x_{t}(t>0)$, which are not observable by the government.

The efficiency parameter $x$ is distributed on $\left[x^{l}, x^{h}\right]$, according to the cumulative distribution function $G(x)$, with density $g(x)$ and $g\left(x^{l}\right), g\left(x^{h}\right)>0$, which is common knowledge. The function $G(x)$ is such that $\phi(x)=\frac{1-G(x)}{g(x) x}$ is monotone and decreasing, with $g\left(x^{l}\right) \geq 1 / x^{l}$. Notice that this condition is strictly weaker than the standard increasing hazard rate assumption (see, e.g., Guesnerie \& Laffont, 1984; Jullien, 2000).

Finally, as standard in the real option approach to investment under uncertainty, we assume that all parties are riskneutral. Indeed, while complicating the analysis, introducing risk aversion would simply lead to an erosion of the project value and an increase of the option value of waiting to invest (Hugonnier \& Morellec, 2013), without qualitatively altering our main findings. 


\section{4 | THE PRIVATE PROJECT VALUE}

Before looking at the government's optimal offer, let's first examine the project value to the firm after investing.

Denoting with $t>0$ the time of investment and working backwards, the private value is given by (see Appendix A):

$$
V\left(x_{t}, x_{T}\right) \equiv \frac{x_{t}-c}{r}-\left(\frac{x_{t}}{x_{T}}\right)^{\beta_{2}}\left(\frac{x_{T}-c}{r}+L\right)
$$

where $r$ is the discount rate, $T$ is the unknown future time the firm will eventually breach the contract, and $\beta_{2}<0$ is the negative root of the characteristic equation $\Psi(\beta)=\left(\sigma^{2} / 2\right) \beta(\beta-1)-r=0$.

The first term on the right-hand side (RHS) of Equation (2) measures the expected present value of total profits if the firm never quits the project, while the second term measures the exit option value. Thus, to maximize the project's value, the firm should cut back the option value by identifying the optimal revenue threshold $x_{T}$ for terminating the contract.

Defining $x_{T}=x^{E}$ as the optimal "exit trigger," this is given by: ${ }^{11}$

$$
x^{E}=\frac{\beta_{2}}{\beta_{2}-1}(c-r L)
$$

Equation (3) shows the relationship between $x^{E}$ and the exit fee $L$. Intuitively, other things being equal, the higher is $L$, the lower is $x^{E}$. For instance, if the government decided to lock-in the firm, by imposing a high fee (i. e. , $L \geqslant \frac{c}{r}$ ), then $x^{E}=0$. In other words, the firm will never find it convenient to walk away. At the opposite extreme, if $L=0$, then $x^{E}=\frac{\beta_{2}}{\beta_{2}-1} c>0$.

Since $0<\frac{\beta_{2}}{\beta_{2}-1}<1$, and thus, $x^{E}<c-r L$, Equation (3) implies that, because of uncertainty and because the decision to quit is irreversible, the firm will tend to postpone the exercise of the exit option, even while losing money, in the hope of recovering previous losses.

Finally, by substituting (3) into (2), we get:

$$
V\left(x_{t}\right)=\frac{x_{t}-c}{r}+O\left(x_{t}\right) \text { for } x_{t} \geq x^{E}
$$

where $O\left(x_{t}\right)=-\left(\frac{x_{t}}{x^{E}}\right)^{\beta_{2}} \frac{x^{E}}{\beta_{2} r}>0$ represents the value of the exit option, with $\frac{\partial O}{\partial x_{t}}=-\left(\frac{x_{t}}{x^{E}}\right)^{\beta_{2}-1} / r<0$.

The simple intuition is that, if the firm was allowed to invest only when revenues are relatively high, the probability of reaching the lower boundary $x^{E}$ will decline, and thus, also the option value. Moreover, since $\frac{\partial O}{\partial L}=-\left(\frac{x t}{x^{E}}\right)^{\beta_{2}}<0$, the higher is the fee, the lower is the value of the exit option.

\section{5 | REVENUE MAXIMIZATION}

\section{1 | The government's objective function}

Armed with these insights, we now turn to the government's problem, which consists of identifying the timing of project implementation (i.e., the optimal revenue threshold for investing) and the mix of direct capital funding $(S)$ and exit option (i.e., exit fee $L$ ) providing the best balance between expected public benefits and public costs.

Since the government is committed to ensuring service continuity, granting an exit option implies the risk of having to resume a financially loss-making activity. Specifically, since the government will incur the same cash-flows that the firm would have incurred, the expected negative private ("market") value needs to be booked on the government's balance sheet. ${ }^{12}$

Therefore, denoting with $\tau$ the stochastic time of investment and with $x_{\tau}$ the level of firm's revenues at the moment of investment, the government's objective function to be optimized at $t=0$ can be written as follows (see Appendix A):

$$
R\left(x, x_{\tau}\right)=\left(\frac{x}{x_{\tau}}\right)^{\beta_{1}}\left[\frac{b}{r}-\left(S+O\left(x_{\tau}\right)\right)\right]
$$


where $\beta_{1}>1$ is the positive root of the characteristic equation $\Psi(\beta), \frac{b}{r}$ is the total value of public benefits, and $S+O\left(x_{\tau}\right)$ is the total (direct and indirect) public cost.

We proceed by first solving the government's maximization problem under symmetric information (Section 5.2) and then turning to the case where the firm holds private information about the project's profit potential (Section 5.3).

\section{2 | Symmetric information}

The government's problem can be broken into two parts. The first part consists of identifying the optimal revenue threshold for investing ("the investment trigger value"). The second part involves determining the minimal capital grant needed to enforce the optimal trigger as a function of the exit fee.

Rearranging Equation (5), the government's expected payoff can be rewritten as follows:

$$
R\left(x, x_{\tau}\right)=W\left(x, x_{\tau}\right)-F\left(x, x_{\tau}\right)
$$

where $W\left(x, x_{\tau}\right) \equiv\left(\frac{x}{x_{\tau}}\right)^{\beta_{1}}\left(\frac{b}{r}+\frac{x_{\tau}-c}{r}-I\right)$ represents the total economic value, that is, the benefits received by all parties net of investment and $\mathrm{O} \& \mathrm{M}$ costs, and $F\left(x, x_{\tau}\right) \equiv\left(\frac{x}{x_{\tau}}\right)^{\beta_{1}}\left[\frac{x_{\tau}-c}{r}-\left(I-S-O\left(x_{\tau}\right)\right)\right]$ is the private project value, with the second term in squared brackets measuring the cost of investing, given by the capital outlay $I$ net of the public grant $S$ and the private value of the exit option $O\left(x_{\tau}\right)$.

The government's optimization problem can thus be written as follows:

$$
\begin{gathered}
\max _{x_{\tau}, S} R\left(x, x_{\tau}\right)=\max _{x_{\tau}, S}\left[W\left(x, x_{\tau}\right)-F\left(x, x_{\tau}\right)\right] \\
F\left(x, x_{\tau}\right) \geq 0
\end{gathered}
$$

For any given exit fee $L$ and, thus, option value $O\left(x_{\tau}\right)$, the government maximizes his own revenue (6) by choosing, on the one hand, the investment trigger value $x_{\tau}$ that maximizes $W\left(x, x_{\tau}\right)$ and, on the other, a transfer $S$ such that $F\left(x, x_{\tau}\right)=0$.

Denoting with $x_{\tau}=x_{\tau^{W}}$ the welfare-maximizing (first-best) trigger value, this is given by:

$$
x_{\tau^{W}}=\frac{\beta_{1}}{\beta_{1}-1}(c-b+r I)
$$

For technical convenience, in the following we ssume that $x<x_{\tau}{ }^{W}$, which implies that it would not be economically efficient to immediately $(t=0)$ invest.

In Equation (8), the multiplier $\frac{\beta_{1}}{\beta_{1}-1}>1$ implies that the first-best trigger $x_{\tau^{W}}$ is higher than the long-run average entry cost (i.e., $c-b+r I>0$ ). In other words, even while taking into account the external benefits $b$, because of uncertainty and the irreversibility of the investment it is advisable to delay project implementation beyond the point where the economic net present value (NPV) becomes positive (Dixit \& Pindyck, 1994).

Having determined $x_{\tau^{W}}$, we can derive the transfer $S^{W}$ which drives the project's private value down to zero:

$$
S^{W}=I-O\left(x_{\tau^{W}}\right)-\frac{x_{\tau^{W}}-c}{r}=\frac{b}{r}-\frac{1}{\beta_{1}-1}\left(\frac{c-b}{r}+I\right)-O\left(x_{\tau^{W}}\right)
$$

Notice that $S^{W}<\frac{b}{r}$. In other words, the optimal capital grant, that is, the one needed to bridge the gap between the privately and socially optimal revenue threshold for investing, is lower than the standard Pigouvian "compensation" for positive externalities. The reason is twofold. First, as implied by (8), it would not be advisable to fully internalize the external benefits because this would lead the firm to accelerate investment inefficiently. Second, the grant needed to bridge that gap is reduced by the exit option, which lowers the private cost of committing a capital outlay.

To summarize, the main findings are as follows. First, not surprisingly, under symmetric information, revenuemaximization (rather than welfare-maximization) does not imply a distortion with respect to the economically efficient timing of investment. In other words, a government focused on his own maximum payoff will find it optimal to implement the project at the same time that a benevolent social planner would choose. 
Second, the government needs to calibrate direct subsidies on capital costs against the exit option's private value. Since the latter depends on the exit fee, this means that the decision about capital funding should not be divorced from the value of $L$ set out in the contract. For instance, if the government decided to lock-in the firm, by setting $L \geq \frac{c}{r}$, the up-front subsidy required to trigger investment optimally would amount to $\frac{b}{r}-\frac{1}{\beta_{1}-1}\left(\frac{c-b}{r}+I\right)$. At the opposite extreme, if the firm was allowed to quit the project without paying any fee, the public contribution to investment costs should be reduced by $O\left(x_{\tau^{W}}, L=0\right)$.

Having said this, under symmetric information the granting of an exit option, as a complement to capital funding, would not bring by itself any particular financial benefit to the government. Indeed, working on Equations (6) and (9), it is easy to show that an increase of the exit option value would not increase the government's expected payoff $\left(\frac{\partial R}{\partial L}=0\right)$. The reason is that the government's marginal gains in terms of up-front savings $\left(\frac{\partial S^{W}}{\partial L}=-\frac{\partial O\left(x_{\tau} W\right)}{\partial L}>0\right)$ would be entirely offset by the lower project's market value at the time the option will be exercised by the firm $\left(\frac{\partial V}{\partial L}=\frac{\partial O\left(x_{x} W\right)}{\partial L}<0\right)$ and, thus, by the higher resumption cost.

\section{3 | Asymmetric information}

We now turn to the case where the initial value $x$, as well as the future realizations of the process (1), are known by the firm but not by the government.

According to the standard direct-revelation mechanism approach, the government should offer at $t=0$ a menu of contracts $(\tau, S(\tau))$ that specifies, as a function of the investment time $\tau$, a payment $S(\tau)$ such that the firm will find it optimal to invest at $\tau$. The mechanism should be incentive-compatible, in the sense that, whatever is her type $x \in\left[x^{l}, x^{h}\right]$, the firm maximizes her expected utility by truthfully reporting, at each time $t \geq 0$, the realization of $x_{t}$.

Unfortunately, since the space of communication strategies between the parties (i.e., the times of investment among which the firm can choose) could be very rich, the standard incentive-compatible mechanism is in general hard to be implemented (Bergemann \& Valimaki, 2018; Board, 2007; Pavan et al., 2014).

An alternative approach has been developed by Kruse and Strack $(2015,2019)$, who show that, if the government intends to enforce a certain timing $\tau$ (i.e., an investment trigger $x_{\tau}$ ), he could rely on a much simpler direct revelation mechanism which does not require an exchange of information between the parties about the realizations of the state variable, with the exception of the initial value $x$.

Under some regularity conditions, Kruse and Strack show that, for any given $x_{\tau}$, there exists a transfer $S$, independent of the future realizations of $x_{t}$, which specifies the payment due at the actual time of investment, such that it becomes optimal for the firm to invest when $x_{\tau}$ is reached for the first time Furthermore, by interpreting $x_{\tau}$ as a reflecting barrier, ${ }^{13}$ the Authors show that the transfer $S$ admits a closed-form solution, given by the expected present value of all future revenues that the firm, once $x_{\tau}$ is reached, would loose if $x_{t}$ was kept below $x_{\tau}$ forever.

Since $S$ is independent of $x_{t}$, the transfer happens to be ex-post incentive-compatible. In other words, if the firm has not invested up to $t$, she will never find it optimal to invest before $x_{\tau}$, and there is no reason why she should change strategy in the future. That is,

$$
x_{\tau}=\arg \max F\left(x_{t}, x_{\tau} ; S\right) \text { for all } t<\tau
$$

where $\tau=\inf \left(t>0 ; x_{t}=x_{\tau}\right)$ and $F\left(x_{t}, x_{\tau} ; S\right)$ is the private project value.

Using these arguments, the firm will invest the first time revenues hit $x_{\tau}$, with the latter given by (see Appendix B): ${ }^{14}$

$$
\frac{\beta_{1}-1}{\beta_{1}} x_{\tau}+r\left[S-\frac{x_{\tau}}{\beta_{1}} \frac{\partial O}{\partial x_{\tau}}\right]=c+r\left(I-O\left(x_{\tau}\right)\right)
$$

Condition (11) simply says that the firm will invest when the expected marginal cost (the RHS) is equal to the expected marginal benefit (the left-hand side [LHS]). This implies that the government can govern the timing of investment either directly, by subsidizing capital costs, or indirectly, by increasing the exit option's private value.

Hence, working backwards, a sufficient condition for a contract to be ex-ante incentive-compatible is when the firm announces the true initial value $x$. Specifically, by substituting (11) into (10), the value to invest for a firm of type $x$ is given by (see Appendix B): 


$$
F\left(x, x_{\tau}\right)=\left(\frac{x}{x_{\tau}}\right)^{\beta_{1}} \frac{x_{\tau}}{\beta_{1} r}\left[1+r \frac{\partial O}{\partial x_{\tau}}\right]=\left(\frac{x}{x_{\tau}}\right)^{\beta_{1}} \frac{x_{\tau}}{\beta_{1} r}\left[1-\left(\frac{x_{\tau}}{x^{E}}\right)^{\beta_{2}-1}\right] \text { for } \quad x^{E}<x<x_{\tau}
$$

where the term $\frac{x_{\tau}}{\beta_{1} r}\left[1-\left(\frac{x_{\tau}}{x^{E}}\right)^{\beta_{2}-1}\right]$ is the NPV of the project at the moment of investment.

Compared with other incentive-compatible methods, the mechanism proposed by Kruse and Strack has three attractive features.

First, since the transfer is independent of the state variable's future realizations, it can be paid even when private revenues are not observable, that is, when alternative mechanisms, such as contingent-pay schemes, are not implementable.

Second, since the transfer is only contingent to the observable investment decision, there is no need of any further transmission of information between the parties. In other words, the government only needs to know that the investment was made, rather than the reasons why it has happened (Board, 2007).

Finally, since, once the contract has been awarded (at $t=0$ ), the firm has no further incentives to misreport, the government can learn the true value of $x_{t}$ at the time of exit by the firm, that is, $x^{E}$.

The following Lemma allows us to extend Kruse and Strack's results to the case where, unlike their model, the firm holds an exit option.

Lemma 1. Letting $x_{\tau}$ an arbitrary investment trigger and $\tilde{x}_{t}$ a version of the process $x_{t}$ reflected at $x_{\tau}$, the stopping time $\tau=\inf \left(t>0 / x_{t}=x_{\tau}\right)$ can be implemented by the following incentive-compatible transfer:

$$
S=I-O\left(x_{\tau}\right)-\frac{x_{\tau}-c}{r}+E_{\tau}\left\{\int_{\tau}^{\infty} e^{-r(t-\tau)}\left|\frac{\partial O}{\partial x_{t}}\left(x_{\tau}\right)\right| d\left(x_{t}-\tilde{x}_{t}\right)\right\}=I-O\left(x_{\tau}\right)-\frac{x_{\tau}-c}{r}+\frac{x_{\tau}}{\beta_{1} r}\left[1-\left(\frac{x_{\tau}}{x^{E}}\right)^{\beta_{2}-1}\right]
$$

Proof. See Appendix C.

Comparison between Equations (9) and (13) shows that, as in the case of symmetric information, the transfer $S$ should cover the difference between the capital outlay $I$ and the expected present value of operating profits, net of the exit option value. However, under asymmetric information, the transfer must be increased by an additional payment such that the firm will not find it convenient to delay project implementation beyond the government's desired revenue threshold $x_{\tau}$.

Specifically, since for $t \geq \tau$ the firm's marginal incentive to delay is $d\left(x_{t}-\tilde{x}_{t}\right)$, the first line in Equation (13) shows that the information rents can be determined by simply calculating the expected present value of all future revenues the firm would loose by keeping $x_{t}$ below $x_{\tau}$. However, since the firm enjoys an exit option, the lost revenues are remunerated by the government at a lower rate than the interest rate $r$, namely, at $\left|\frac{\partial \mathrm{O}}{\partial \mathrm{x}_{\mathrm{t}}}\right|<1 / r{ }^{15}$

Moreover, the second line in Equation (13) shows that the integral admits a closed-form solution, and the information rents, represented by the last term of the RHS, are nothing but the NPV to invest evaluated at $x_{\tau}$, that is, $F\left(x_{\tau}, x_{\tau}\right)$.

Armed with these insights, let's return to the government's optimization problem. Since an investment time $\tau=\inf \left(t>0 ; x_{t}=x_{\tau}\right)$ can be implemented by the transfer (13), by the standard mechanism design approach (Laffont \& Martimort, 2002) we can confine the analysis on menus of ex-ante incentive-compatible contracts which induce the firm to reveal her initial type $x \in\left[x^{l}, x^{h}\right]$. Thus, the government's problem reduces to choosing the investment trigger $x_{\tau}(x)$ which maximizes the following objective function:

$$
\mathscr{R}\left(x, x_{\tau}(x)\right) \equiv \int_{x_{l}}^{x_{h}} R\left(x, x_{\tau}(x)\right) g(x) d x
$$

By substituting Equation (13) into (14) and rearranging, the government's optimization problem becomes:

$$
\max _{x_{\tau}(.)} \mathscr{R}\left(x, x_{\tau}(x)\right)=\max _{x_{\tau}(.)} \int_{x_{l}}^{x_{h}} \hat{W}\left(x, x_{\tau}(x)\right) g(x) d x
$$

subject to: 


$$
\begin{gathered}
\frac{d x_{\tau}(x)}{d x}<0 \\
F\left(x, x_{\tau}(x)\right) \geq 0
\end{gathered}
$$

where $\hat{W}\left(x, x_{\tau}(x)\right) \equiv W\left(x, x_{\tau}(x)\right)-\frac{1-G(x)}{g(x)} F_{x}\left(x, x_{\tau}(x)\right)$ represents the "virtual welfare" (Myerson, 1981) which incorporates the incentive-compatibility constraint.

To ensure that the contract duration is always positive and to avoid bunching, we add the following assumption, which guarantees that the second order condition (15.2) is satisfied and that the optimal investment trigger $x_{\tau}(x)$ is decreasing in $x \in\left[x^{l}, x^{h}\right]{ }^{16}$

Assumption 1. $\frac{x^{E}}{x_{\tau^{W}}}<K \min \left[\frac{g\left(x^{l}\right) x^{l}-1}{\beta_{1}-1}, 1\right]$, where $K=\left(\frac{\beta_{1}-1}{\beta_{1}-\beta_{2}}\right)^{1 / 1-\beta_{2}}<1$.

The solution is summarized in the following proposition.

Proposition 1. Under Assumption 1, for any given exit fee $L<\frac{c}{r}$ :

(a) the government's revenue is maximized by the investment time $\tau^{R}(x)=\inf \left(t>0 / x_{t}=x_{\tau^{R}}(x)\right)$, where the investment trigger $x_{\tau^{R}}(x)$ is defined by:

$$
x_{\tau^{R}}(x)=x_{\tau^{W}}+\left[x_{\tau^{W}}-r\left(\beta_{1}-\beta_{2}\right) O\left(x_{\tau^{R}}(x)\right)\right] \frac{\phi(x)}{1-\phi(x)}
$$

(b) the transfer that implements $\tau^{R}(x)$ is:

$$
S^{R}(x)=\frac{b}{r}-\frac{\beta_{1}-\beta_{2}}{\beta_{1}} O\left(x_{\tau^{R}}(x)\right)-\left(\frac{\beta_{1}-1}{\beta_{1}}\right) \frac{x_{\tau^{R}}(x)-x_{\tau^{W}}}{r}
$$

with $\frac{\partial S^{R}(x)}{\partial x}>0$.

Proof. See Appendix D.

Equation (16.1) shows that (except for the firm with the highest revenue potential, $\left.x=x^{h}\right), x_{\tau^{R}}(x)>x_{\tau^{W}} \cdot{ }^{17}$ In other words, a revenue-maximizing government will find it convenient to delay project implementation relative to the firstbest. The reason is that the timing distortion allows the government to squeeze information rents and, thus, to save on capital subsidies. Hence, as always happens in a principal-agent problem, the government faces a rent-efficiency tradeoff. Indeed, comparison between (16.2) and (9) shows that (except for $x=x^{h}$ ) the optimal capital grant is lower than the one paid under full information: $S^{R}(x)<S^{W}$.

Moreover, Equation (16.1) confirms the result underlined by condition (11), that is, the government can always reduce the rents left to all inframarginal types by increasing the value of the exit option. Indeed, taken together, Equations (16.1) and (16.2) show that the investment is accelerated (and so more efficient), and the subsidy is lowered for any timing target.

Thus, rents go down. The reason is that, since firms with low revenue potential tend to wait longer before investing, the government needs to limit the rents that need to be paid for high revenue potential firms to induce them to reveal themselves truthfully. The lowering of the exit fee limits the differentiating value of delay and rents left to the firms, thus inducing more efficient investment thresholds at a lower public cost.

We can disentangle the effect of the exit fee on the government's expected payoff by taking the derivative of $R($.) with respect to $L$. This allows us to make the following proposition.

Proposition 2. Since $\frac{\partial \mathscr{R}}{\partial L}$ is always negative for all $L \in\left[0, \frac{c}{r}\right]$, under the optimal contract (16.1) and (16.2) the government will maximize his expected revenue by setting $L=0$.

Proof. See Appendix E. 
To better grasp the intuition behind Proposition 2, we can exploit the Myersonian equivalence between the government's expected revenue and the government's expected virtual surplus. By substituting Equation (16.1) into the virtual surplus $\hat{W}\left(x, x_{\tau}(x)\right)$ and by keeping the dependency of $x_{\tau^{R}} x^{E}$ on $L$, we get (see Appendix E):

$$
\hat{W}\left(x, x_{\tau^{R}}(x, L), L\right)=(1-\phi(x)) F\left(x, x_{\tau^{R}}(x, L), L\right)+\hat{O}\left(x_{\tau^{R}}(x, L), L\right)
$$
where $F\left(x, x_{\tau^{R}}(x, L), L\right)=E_{0}\left(e^{-r \tau^{R}(x, L)}\right) \frac{x_{\tau^{R}(x, L)}}{\beta_{1} r}\left(1-\left(\frac{x_{\tau^{R}}(x, L)}{x^{E}(L)}\right)^{\beta_{2}-1}\right)$ and $\hat{O}\left(x_{\tau^{R}}(x, L), L\right) \equiv-E_{0}\left(e^{-r \tau^{R}(x, L)}\right) \frac{\beta_{2}}{\beta_{1}}\left[1-\beta_{1} \phi(x)\right]$
$O\left(x_{\tau^{R}}(x, L), L\right)$.

The first term on the RHS measures the "virtual value" (Myerson, 1981), that is, the expected surplus extracted from a firm of type $x$, while the second term shows what the government expects to earn by granting an exit option.

By collecting the expected discount factor $E_{0}\left(e^{-r \tau^{R}(x, L)}\right)$, Equation (17) becomes:

$$
\begin{aligned}
& \hat{W}\left(x, x_{\tau^{R}}(x, L), L\right) \\
& =E_{0}\left(e^{-r \tau^{R}(x, L)}\right)\left\{[\underbrace{\frac{x_{\tau^{R}(x, L)}^{\beta_{1} r}}{\beta^{\prime}}\left(1-\left(\frac{x_{\tau^{R}}(x, L)}{x^{E}(L)}\right)^{\beta_{2}-1}\right)}_{\text {NPV at the moment of investment }}-\underbrace{\phi(x) \frac{x_{\tau^{R}(x, L)}}{\beta_{1} r}\left(1-\left(\frac{x_{\tau^{R}}(x, L)}{x^{E}(L)}\right)^{\beta_{2}-1}\right)}_{\text {Information rents }}\right. \\
& +\underbrace{\left.\left(1-\beta_{1} \phi(x)\right) \frac{x_{\tau^{R}(x, L)}}{\beta_{1} r}\left(\frac{x_{\tau^{R}}(x, L)}{x^{E}(L)}\right)^{\beta_{2}-1}\right]}_{\text {Optionpremium }}]\}
\end{aligned}
$$

By totally differentiating Equation (18) with respect to $L$, we can analyze the effects of a reduction of the exit fee. The overall impact of a change of $L$ on the government's expected revenue can be decomposed into four effects (see Appendix E):

$$
\frac{\partial \hat{W}}{\partial L}=\left[\begin{array}{c}
\left(1-\beta_{1}\right) \frac{\hat{W}}{x_{\tau}} \frac{\partial x_{\tau}}{\partial x^{E}} \\
+F\left(x, x_{\tau}\right)\left(1-\beta_{2}\right) \frac{\left(\frac{x_{\tau}}{x^{E}}\right)^{\beta_{2}-1}}{\left(1-\left(\frac{x_{\tau}}{x^{E}}\right)^{\beta_{2}-1}\right)}\left(\frac{1}{x_{\tau}} \frac{\partial x_{\tau}}{\partial x^{E}}-\frac{1}{x^{E}}\right) \\
-\phi(x) F\left(x, x_{\tau}\right)\left(1-\beta_{2}\right) \frac{\left(\frac{x_{\tau}}{x^{E}}\right)^{\beta_{2}-1}}{\left(1-\left(\frac{x_{\tau}}{x^{E}}\right)^{\beta_{2}-1}\right)}\left(\frac{1}{x_{\tau}} \frac{\partial x_{\tau}}{\partial x^{E}}-\frac{1}{x^{E}}\right) \\
+\left(1-\beta_{2}\right) \hat{O}\left(x_{\tau}\right)\left(\frac{1}{x_{\tau}} \frac{\partial x_{\tau}}{\partial x^{E}}-\frac{1}{x^{E}(L)}\right)
\end{array}\right] \frac{\partial x^{E}}{\partial L}
$$

The first line, inside the square brackets, in Equation (19) captures the effect of the discount rate on the "virtual welfare." Since an increase of the exit option's value reduces the firm's commitment and, thus, accelerates investment, a reduction of $L$ contributes to, ceteris paribus, increasing the government's revenue.

The second line illustrates the effect of a change of $L$ on the surplus (NPV) extracted from the firm, net of the information rents. Since a reduction of $L$ makes the firm more prone to anticipate the exit and, thus, increases the probability that the government will have to resume a financially loss-making activity, a reduction of $L$ brings down the government's revenue.

The third line captures the effect of a change of $L$ on the information rents paid to the firm. Since a reduction of $L$ increases the private value of the exit option and, in so doing, reduces the differentiating value of delay, lowering the value of the exit fee contributes to increasing the government's payoff.

Finally, the fourth line indicates the effect of a change of $L$ upon the exit option's value. The effect is not univocal, since, for any given $L$, the option value varies according to the firm's revenue potential. In fact, while efficient firms attributes a high value to the exit option (because they invest early), firms with a low-revenue potential attach a lower 
value to the possibility of quitting the project. Hence the effect depends on the sign of the term $\left[1-\beta_{1} \phi(x)\right]$, and is positive, that is, the government will benefit of a reduction of $L$, if $\left[1-\beta_{1} \phi(x)\right]>0$, and negative otherwise. The former occurs when, given the level of uncertainty about future revenues, the distribution of types $G(x)$ is such that $g\left(x^{l}\right) x^{l}>\beta_{1}$, that is, when even a firm with the lowest possible revenue potential would attach a nonnegligible value to the exit option. Alternatively, the same occurs when, given the distribution of types, the uncertainty is very high, in which case $\beta_{1}$ decreases and, thus, the more likely is that $\left[1-\beta_{1} \phi(x)\right]>0$.

Thus, the first effect is positive (i.e., the government's payoff increases as $L$ reduces), the second effect is negative, the third effect is positive and the fourth effect is positive if $\left[1-\beta_{1} \phi(x)\right]>0$, and negative otherwise. Yet, Proposition 2 shows that the net impact of a reduction of $L$ is always to increase the government's expected payoff.

To summarize, when private revenues are uncertain, and the firm holds private information on the revenue potential, the government can increase his own payoff by lowering the exit fee. Essentially, the reason is that, to squeeze information rents, the government does not need to delay project implementation as much as it would occur if cash payments only sustained the investment. Stated differently, granting an exit option allows the government to increase the "productivity" of direct capital funding in terms of investment acceleration.

Notice that this result is broadly in line with the findings presented in Arve and Martimort (2016) who, using a two-period model with uncorrelated shocks, show (Proposition 2, p. 3254) that when the agent is risk-adverse in the second period, the principal can relax the first-period incentive-compatibility constraint by offering the agent higher profits in the second period. Here we obtain a similar result, by introducing an exit option (which reduces potential firm's losses in the event of unfavorable revenue variances) within a continuous-time principal-agent model with risk-neutral agents.

Indeed, within our model, the incentives used to spur investment can be thought as a compound option since, on the one hand, the firm is entitled to receive a lump-sum subsidy upon investment (a call option) and, on the other, she is allowed to terminate the contract at a strike price (a put option). While efficient firms attach a higher value to the possibility of quitting the project, the reverse applies to less efficient firms, which are more prone to postponing investment and, thus, attribute a greater value to the call option. This negative correlation reduces the differentiating value of delay across different types and rents left to the firm, increasing the government's expected payoff. ${ }^{18}$

\section{6 | FINAL REMARKS}

PPPs for the provision of public infrastructures and services have gained increased interest over the past decades. While many PPPs have been success stories, others have largely failed to meet expectations. For instance, the frequency of early terminations and renegotiations has raised concern about the PPPs' real benefits over direct provision of public services or more conventional procurement methods, and has stimulated a debate on how to prevent or mitigate the effects of breach of contracts.

Our paper contributes to this debate by arguing that the project's abandonment by the private party may not constitute a problem per se as long as the risk of termination is properly ("proactively") accounted for at the time of contract formation, by calibrating public subsidies on capital costs against the exit option's private value. Since the latter depends on the penalties for breach of contract, this means that the decision about capital funding should not be divorced from the contractual provisions for early termination of service.

Granting of an exit option, allowing the private partner to abandon an unprofitable venture, may prove especially useful in the case of risky projects and private information on the returns from investment. Specifically, we have shown that blending direct subsidies and option-like incentives can spur investment at a relatively lower public cost compared with lock-in contracts, even while taking into account the potential budgetary impacts of insourcing a financially loss-making activity.

\section{ACKNOWLEDGMENTS}

We thanks the associate editor and two anonymous referees who helped us to improve both the contents and the exposition of this paper. We also benefited from conversations with Amedeo Pugliese and Ravi Prakash Rao Yerraji as well as from comments of the participants in seminars and conferences where preliminary versions were presented. The usual disclaimer applies. 


\section{ENDNOTES}

${ }^{1}$ Other papers (see, e.g., Alonso-Conde et al., 2007; Iossa et al., 2007) have instead focused on the government's decision to early terminate the contract unilaterally, even if the partner has performed satisfactorily. Unlike the situation considered in this paper, the government might decide to take-over a (beyond expectations) financially profitable venture, in which case, according to the "market value principle," the government will have to indemnify the partner for the loss of expected earnings (European PPP Expertise centre-EIB, 2013).

${ }^{2}$ Governments' reluctance to explicitly grant the right to quit a loss-making activity may be explained by several factors, such as public concern about service continuity, political economy considerations, public law constraints or other legal challenges (e.g., issues related to the burden of proof in civil actions).

${ }^{3}$ Here and in the following we avoid using terms like "penalty" or "liquidated damages," whose scope and legal consequences vary across different jurisdictions, namely, civil and common-law countries (Di Matteo, 2001; Marin Garcia, 2012). For our purpose, it suffices to think of the "fee" as as a sort of strike price to be paid out if the firm exercises the exit option.

${ }^{4}$ In Section 5, we provide a formal description of the government's objective function.

${ }^{5}$ Alternatively, we could have more general cases where the firm's profit is included in the government's objective function (Engel et al., 2013), but public transfers are financed through distortive taxation (Auriol \& Picard, 2013; Bennett \& Iossa, 2006). However, allowing for these alternative specifications would leave our main findings substantially unchanged.

${ }^{6}$ In many of the applications we have in mind, public benefits may not be constant but, like cash-flows, also evolve over time. For instance, in toll roads, positive externalities generally increase with the traffic diverted from the existing roads, which, in turn, influences the amount of toll revenues. However, as long the process governing the project's externalities is public information, we can generalize our model to allow for this.

${ }^{7}$ The assumption that the firm's reservation utility is zero can be justified on the ground that the provision of public services is normally subject to governmental authorization or licencing. The same reasoning applies in the case of projects involving the production of marketable goods (e.g., renewable energy) which require as input specific assets the government fully controls, such as publicly owned land or state buildings.

${ }^{8}$ In the paper, we assume that the exit fee chosen by the government is legally and costlessly enforceable. However, in the real world, penalties are not always enforced because of the poor quality of the judicial system or the presence of legal standards that limit the governments' discretion when setting penalties (Dosi \& Moretto, 2015). Yet, the issue of enforceability is quite limited in our work, insofar as we show that when it is optimal for the government to incorporate the exit option in the contract, the exit fee should be equal to zero. In other words, the government maximizes revenues by letting the firm walk away without paying any "penalty."

${ }^{9}$ For the sake of simplicity, we assume that the project will be carried out with fixed annual O\&M costs denoted as $c$. Hence, in each period, cash-flows (operating profits) are given by $x_{t}-c$. However, the production of infrastructure services typically requires both fixed and variable O\&M costs, in which case the state variable $x_{t}$ can be interpreted as the difference between revenues, coming from end-users, and variable O\&M costs.

${ }^{10}$ The assumption of a trendless random walk allows us to focus on the pure effect of uncertainty, namely, on the effect of $\sigma$ on both the optimal revenue state for investing and the firm's optimal timing for terminating the contract. However, by the Markov property of (1), our results would not be qualitatively altered by using a nonzero trend for $x_{t}$.

${ }^{11}$ Consistently with Equation (2), the firm's optimal exit time is described by a first passage time $T$ of the state variable $x_{t}$ by a constant threshold $x^{E}$. Formally, $T=\inf \left(t>0\right.$, such that $\left.x_{t}=x^{E}\right)$.

${ }^{12}$ For the same reason, that is, the negative financial NPV, according to the "market value principle," the firm will not receive any compensation for the asset transferred to the government. Indeed, according to this rule, "any compensation to the defaulting Private Partner should be determined by reference to the market value of the PPP contract at the date of termination" (European PPP Expertise CentreEIB, 2013, p. 41). The market value principle was developed in the UK in the late 1990s under the Private Finance Initiative.

${ }^{13} \mathrm{~A}$ reflected process is like a process that has the same dynamics as the original process, but is required to stay below a given barrier whenever the original process tends to exceed it. See Harrison (2013) and Appendix C here for a formal definition of these processes.

${ }^{14}$ Kruse and Strack show that a transfer $S$ exists even when the principal's benefits (i.e., in our framework, $b$ ) are time-dependent (see the previous footnote 3 ), in which case the optimal timing of investment will also be time-dependent. However, in general, a closed-form solution for $x_{\tau}(t)$ (and, thus, for $S(t)$ ) does not exist, and numerical methods are required to reach a solution.

${ }^{15}$ In Appendix C we show that the term $\frac{\partial O}{\partial x_{t}} d\left(\tilde{x}_{t}-x_{t}\right)>0$ represents the cost per unit of the distance through which $x_{t}$ is reflected to keep $x_{t}$ at $x_{\tau}$.

${ }^{16}$ Although it is not the main focus of our work, in Appendix D we briefly discuss the consequences of violating Assumption 1 . We show that when the exit trigger $x^{E}$ is relatively high (i.e., when the exit fee is low), the optimal contract can involve a bunching interval for the most efficient types.

${ }^{17}$ When $x=x^{h}$, then $\phi\left(x^{h}\right)=0$ and $x_{\tau^{R}}\left(x^{h}\right)=x_{\tau^{W}}$. 
${ }^{18}$ A similar result can be found in Board (2007) and Dosi and Moretto (2015) where, however, rent extraction comes through the competitive bid pressure generated by a put option.

${ }^{19}$ Note that the fact that (B.4) is decreasing in $x_{t}$ follows from what Kruse and Strack (2015), call "dynamic single crossing” condition. Arve and Zwart (2014) refer to Equation (B.5) as the ex-post incentive-compatible condition.

\section{ORCID}

Marco Buso (1) http://orcid.org/0000-0002-3102-5097

Michele Moretto (1) http://orcid.org/0000-0002-5892-8165

\section{REFERENCES}

Adkins, R., \& Paxson, D. (2017). Risk sharing with collar options in infrastructure investments. Proceedings of the 21st Annual International Real Options Conference, Boston, USA.

Alonso-Conde, A. B., Brown, C., \& Rojo-Suarez, J. (2007). Public private partnerships: Incentives, risk transfer and real options. Review of Financial Economics, 16, 335-349.

Arve, M., \& Martimort, D. (2016). Dynamic procurement under uncertainty: Optimal design and implications for incomplete contracts. American Economic Review, 106, 3238-3274.

Arve, M., \& Zwart, G. (2014). Optimal procurement and investment in new technologies under uncertainty (TILEC Discussion Paper No. 2014-028).

Auriol, E., \& Picard, P. M. (2013). A theory of BOT concession contracts. Journal of Economic Behavior and Organization, 89, 187-209.

Baron, D., \& Besanko, D. (1984). Regulation, asymmetric information, and auditing. The Rand Journal of Economics, 15, 447-470.

Battaglini, M. (2005). Long-term contracting with Markovian consumers. American Economic Review, 95, 637-658.

Bennett, J., \& Iossa, E. (2006). Building and managing facilities for public services. Journal of Public Economics, 90, $2143-2160$.

Bergemann, D., \& Valimaki, G. (2018). Dynamic mechanism design: An introduction (Cowles Foundation Discussion Paper No. 2102R).

Beuve, J., Moszoro, M. W., \& Saussier, S. (2019). Political contestability and public contract rigidity: An analysis of procurement contracts. Journal of Economics \& Management Strategy, 28, 316-335.

Blank, F. F., Samanez, C. P., Baidya, T. K. N., \& Dias, M. A. G. (2016). Economic valuation of a toll road concession with traffic guarantees and the abandonment option. Production, 26, 39-53.

Board, S. (2007). Selling options. Journal of Economic Theory, 136, 324-340.

Brandao, L. E. T., \& Saraiva, E. (2008). The option value of government guarantees in infrastructure projects. Construction Management of Economics, 26, 1171-1180.

Broer, P., \& Zwart, G. (2013). Optimal regulation of lumpy investments. Journal of Regulation Economics, 44, 177-196.

Calzolari, G., \& Spagnolo, G. (2009). Relational contracts and competitive screening (CEPR Discussion Paper No. 7434). Centre for Economic Policy Research, London. http://www.cepr.org/pubs/dps/DP7434

Di Corato, L., Dosi, C., \& Moretto, M. (2018). Multidimensional auctions for long-term procurement contracts with early-exit options: The case of conservation contracts. European Journal of Operational Research, 267, 368-380.

Cruz, C. O., \& Marques, R. C. (2013). Flexible contracts to cope with uncertainty in public-private partnerships. International Journal of Project Management, 31(3), 473-483. https://doi.org/10.1016/j.ijproman.2012.09.006

Danau, D., \& Vinella, A. (2017). From fixed to state-dependent duration in public-private partnerships. Journal of Economics \& Management Strategy, 26, 636-660.

Demirel, H. C., Leendertse, W., Volker, L., \& Hertogh, M. (2017). Flexibility in PPP contracts—dealing with potential change in the precontract phase. Construction Management and Economics, 35, 196-206.

Dixit, A., \& Pindyck, R. S. (1994). Investment under uncertainty. Princeton University Press.

Dosi, C., \& Moretto, M. (2015). Procurement with unenforceable contract time and the law of liquidated damages. Journal of Law, Economics and Organization, 31, 160-186.

Engel, E., Fischer, R., \& Galetovic, A. (2001). Least-present-value-of-revenue auctions and highway franchising. Journal of Political Economy, 109, 993-1020.

Engel, E., Fischer, R., \& Galetovic, A. (2013). The basic public finance of public-private partnerships. Journal of the European Economic Association, 11, 83-111.

Engel, E., Fischer, R., \& Galetovic, A. (2014). Finance and Public-Private Partnerships. In A Heath, \& M. Read (Eds.), Financial Flows and Infrastructure Financing (pp. 193-223). Reserve Bank of Australia.

Esö, P., \& Szentes, B. (2007). Optimal information disclosure in auctions. The Review of Economic Studies, 74, 705-731.

European PPP Expertise centre-EIB. (2013). Termination and force majeure provisions in PPP contracts. Report of the European PPP Expertise Center.

Forrer, J., Kee, J. E., Newcomer, K. E., \& Boyer, E. (2010). Public-private partnerships and the public accountability question. Public Administration Review, 70, 475-484.

Guash, J. L. (2014). The renegotiation of PPP contracts: An overview of its recent evolution in Latin America. International Transport Forum Discussion Papers No. 2014/18, OECD Publishing, Paris. 
Guesnerie, R., \& Laffont, J. J. (1984). A complete solution to a class of principal-agent problems with an application to the control of a selfmanaged firm. Journal of Public Economics, 25, 329-369.

Harrison, M. J. (2013). Brownian models of performance and control. Cambridge University Press.

Hart, O. (2003). Incomplete contracts and pubic ownership: Remarks and an application to public-private partnerships. The Economic Journal, 113, 69-76.

Hoppe, E. I., \& Schmitz, P. W. (2013). Public-private partnerships versus traditional procurement: Innovation incentives and information gathering. The Rand Journal of Economics, 44, 56-74.

Huang, Y. L., \& Chou, S. P. (2006). Valuation of the minimum revenue guarantee and the option to abandon in BOT infrastructure projects. Construction Management and Economics, 24, 379-389.

Hugonnier, J., \& Morellec, E. (2013). Real options and risk aversion. In A. Bensoussan, S. Peng, \& J. Sung (Eds.), Real options, ambiguity, risk and insurance (pp. 52-65). IOS Press.

Iossa, E., \& Martimort, D. (2015). The simple micro-economics of public private partnerships. Journal of Public Economic Theory, $17,4-48$. Iossa, E., Spagnolo, G., \& Vellez, M. (2007). Contract design in public-private partnerships. Report for the World Bank.

Jin, H., Liu, S., Sun, J., \& Liu, C. (2019). Determining concession periods and minimum revenue guarantees in public-private-partnership agreements. European Journal of Operational Research. https://doi.org/10.1016/j.ejor.2019.12.013

Jullien, B. (2000). Participation constraints in adverse selection models. Journal of Economic Theory, 93, 1-47.

Kelman, S. (1990). Procurement and public management: the fear of discretion and the quality of government performance. The AEI Press.

Kelman, S. (2002). Remaking federal procurement. Public Contracts Law Journal, 31, 581-622.

Kruse, T., \& Strack, P. (2015). Optimal stopping with private information. Journal of Economic Theory, 159, $702-727$.

Kruse, T., \& Strack, P. (2019). An inverse optimal stopping problem for diffusions. Mathematics of Operations Research, 44(2), 423-439.

Laffont, J. J., \& Martimort, D. (2002). The theory of incentives: The principal-agent model. Princeton University Press.

Marin Garcia, I. (2012). Enforcement of Penalty Clauses in Civil and Common Law: A puzzle to be solved by the contracting parties. European Journal of Legal Studies, 5, 98-123.

Martimort, D., \& Pouyet, J. (2008). To build or not to build: normative and positive theories of private-public partnerships. International Journal of Industrial Organization, 26, 392-411.

Martins, J., Marques, R., \& Cruz, C. (2015). Real options in infrastructure: Revisiting the literature. Journal of Infrastructure System, 21(1), 04014026.

Di Matteo, L. A. (2001). A theory of efficient penalty: Eliminating the law of liquidated damages. American Business Law Journal, 38, 633-733.

Myerson, R. B. (1981). Optimal auction design. Mathematics of Operations Research, 6, 58-73.

Pavan, A., Segal, I., \& Toikka, J. (2014). Dynamic mechanism design: A myersonian approach. Econometrica, 82, 601-653.

PPIAF. (2019). Overview of PPP experience in toolkit for Public-Private Partnerships in roads and highways. https://ppiaf.org/sites/ppiaf. org/files/documents/toolkits/highwaystoolkit/6/pdf-version/1-21.pdf

Sadka, E. (2006). Public-private partnerships: a public economics perspective (IMF Working Paper No 06/77).

Saussier, S., \& Brux, J. (2018). The economics of public-private partnerships. theoretical and empirical developments. Springer International Publishing.de.

Scandizzo, P. L., \& Ventura, M. (2010). Sharing risk through concession contracts. European Journal of Operational Research, $207,363-370$.

Scott, R. E., \& Triantis, G. G. (2004). Embedded options and the case against compensation in contract law. 104 Columbia Law Review, 104, 1428-1491.

Soumare, I., \& Lai, V. S. (2016). An analysis of government loan guarantees and direct investment through public-private partnerships. Economic Modelling, 59, 508-519.

Takashima, R., Yagi, K., \& Takamori, H. (2010). Government guarantees and risk sharing in public-private partnerships. Review of Financial Economics, 19, 78-83.

World Bank. (2017). Public-private partneships. Reference guide. The International Bank for Reconstruction and Development/The World Bank.

World Bank. (2019). Assessing and managing credit risk from contingent liabilities: a focus on government guarantees. The International Bank for Reconstruction and Development/The World Bank.

Yang, Y., \& Zhang, W. (2010). The future of PPPs in China. A preliminary assessment. In P. Ulio (Ed.), Public-private partnerships. Success and failure factors for in-transition countries (pp. 280-314). University Press of America.

Zhang, X., \& Xiong, W. (2015). Renegotiation and early termination in public private partnerships. International Journal of Architecture, Engineering and Construction, 4, 204-213.

How to cite this article: Buso, M., Dosi, C., \& Moretto, M. (2021). Do exit options increase the value for money of public-private partnerships? Journal of Economics \& Management Strategy, 1-22.

https://doi.org/10.1111/jems.12440 


\section{APPENDIX A: EQUATIONS (2) AND (5)}

Using the law of iterated expectations, the project's private value $V\left(x_{t}, x_{T}\right)$ can be expanded as follows:

$$
V\left(x_{t}, x_{T}\right) \equiv E_{t}\left[\int_{t}^{T} e^{-r(s-t)}\left(x_{s}-c\right) d s-e^{-r(T-t)} L\right]=\frac{x_{t}-c}{r}-E_{t}\left(e^{-r(T-t)}\right) E_{T}\left[\int_{T}^{\infty} e^{-r(s-T)}\left(x_{s}-c\right) d s+L\right]
$$

By the "expected discount factor" $E_{t}\left(e^{-r(T-t)}\right)=\left(\frac{x_{t}}{x_{T}}\right)^{\beta_{2}}$ we obtain the expression in the text, where $\beta_{2}<0$ is the negative root of the characteristic equation $\Psi(\beta)=\left(\sigma^{2} / 2\right) \beta(\beta-1)-r=0$ (Dixit and Pindyck, 1994).

The government's objective function is:

$$
\begin{aligned}
R\left(x, x_{\tau}\right) & =E_{0}\left(e^{-r \tau}\right)\left[\int_{\tau}^{\infty} e^{-r(t-\tau)} b d t-S\right]+E_{0}\left\{e^{-r T}\left[\int_{T}^{\infty} e^{-r(t-T)}\left(x_{t}-c\right) d t+L\right]\right\} \\
& =E_{0}\left(e^{-r \tau}\right)\left[\left(\frac{b}{r}-S\right)+E_{\tau}\left(e^{-r(T-\tau)}\right)\left(\frac{x^{E}-c}{r}+L\right)\right]
\end{aligned}
$$

Recalling that, by Equation (2), $E_{\tau}\left(e^{-r(T-\tau}\right)\left[\frac{x^{E}-c}{r}+L\right]=-O\left(x_{\tau}\right)$, where $x_{\tau}$ is the level of cash flows at the moment of investment, (A.2) reduces to:

$$
R\left(x, x_{\tau}\right)=E_{0}\left(e^{-r \tau}\right)\left[\frac{b}{r}-\left(S+O\left(x_{\tau}\right)\right)\right]=\left(\frac{x}{x_{\tau}}\right)^{\beta_{1}}\left[\frac{b}{r}-\left(S+O\left(x_{\tau}\right)\right)\right]
$$

where, now, the expected discount factor is $E_{0}\left(e^{-r \tau}\right)=\left(\frac{x}{x_{\tau}}\right)^{\beta_{1}}$, and $\beta_{1}>1$ is the positive root of the characteristic equation $\Psi(\beta)$.

\section{APPENDIX B: EQUATIONS (11) AND (12)}

For every transfer $S$, the privately optimal investment strategy can be represented by a cut-off function $x_{\tau}$ such that it becomes optimal to invest the first time $x_{t}$ hits $x_{\tau}$.

Let's suppose that a transfer $S$ independent of $x_{t}$ exists. Thus, in the range where $x^{E}<x_{t}<x_{\tau}, F\left(x_{t}, x_{\tau}\right)$ satisfies the first-order condition:

$$
\left(\frac{x_{t}}{x_{\tau}}\right)^{\beta_{1}}\left\{-\beta_{1}\left(\frac{1}{x_{\tau}}\right)\left[\frac{x_{\tau}-c}{r}-\left(I-O\left(x_{\tau}\right)\right)+S\right]+\left[\frac{1}{r}+\frac{\partial O\left(x_{\tau}\right)}{\partial x_{\tau}}\right]\right\}=0
$$

while the second-order condition is always satisfied:

$$
\left(\frac{x_{t}}{x_{\tau}}\right)^{\beta_{1}}\left\{\beta_{1}\left(\frac{1}{x_{\tau}}\right)\left[\left(\frac{1}{x_{\tau}}\right)\left(\frac{x_{\tau}-c}{r}-\left(I-O\left(x_{\tau}\right)\right)+S\right)-\frac{1}{r}-\frac{\partial O\left(x_{\tau}\right)}{\partial x_{\tau}}\right]+\frac{\partial^{2} O\left(x_{\tau}\right)}{\partial x_{\tau}^{2}}\right\}<0
$$

Substituting (B.1) into the firm's value function, we get:

$$
F\left(x_{t}, x_{\tau}\right)=\left(\frac{x_{t}}{x_{\tau}}\right)^{\beta_{1}} \frac{x_{\tau}}{\beta_{1} r}\left[1-\left(\frac{x_{\tau}}{x^{E}}\right)^{\beta_{2}-1}\right] \text { for } \quad x^{E}<x_{t}<x_{\tau}
$$

Now, let's define the firm's continuation value as:

$$
u\left(x_{t}\right)=F\left(x_{\tau}\right)+S-F\left(x_{t}, x_{\tau}\right)=\frac{x_{\tau}}{\beta_{1} r}\left[1-\left(\frac{x_{\tau}}{x^{E}}\right)^{\beta_{2}-1}\right]+S-\left(\frac{x_{t}}{x_{\tau}}\right)^{\beta_{1}} \frac{x_{\tau}}{\beta_{1} r}\left[1-\left(\frac{x_{\tau}}{x^{E}}\right)^{\beta_{2}-1}\right]
$$


Equation (B.4) indicates the firm's willingness to pay for holding the option to delay the investment beyond the current value of revenues $x_{t}$. By definition, the continuation value is nonnegative, that is, $u\left(x_{t}\right)-S \geq 0$. If $u\left(x_{t}\right)-S>0$, the firm will continue to keep the option alive, while if $u\left(x_{t}\right)-S=0$ there will be no gain to go forward. Moreover, $\beta_{2}>1$ implies that $u\left(x_{t}\right)$ is decreasing in $x_{t} \cdot{ }^{19}$

$$
\frac{d u\left(x_{t}\right)}{d x_{t}}=-\frac{1}{r}\left(\frac{x_{t}}{x_{\tau}}\right)^{\beta_{1}-1}\left[1-\left(\frac{x_{\tau}}{x^{E}}\right)^{\beta_{2}-1}\right]<0 \text { for } x^{E}<x_{t}<x_{\tau}
$$

Since, at every point in time, the firm can decide whether to invest or postpone the decision, if it is optimal to invest at $x_{t}$, it is optimal to invest at $x_{t}^{\prime}>x_{t}$. Thus, since the marginal incentive to keep the option alive decreases as $x_{t}$ increases, for any transfer $S$ there is a level of revenues $x_{\tau}$ where is optimal to invest.

\section{APPENDIX C: PROOF OF LEMMA 1}

We prove the Lemma in two steps by adapting the procedure developed by Kruse and Strack (2015, Theorem 1) and Kruse and Strack (2019, Theorem 11).

\section{First step}

For any time-autonomous investment time $\tau$ (i.e., revenue threshold $x_{\tau}$ ), the associated transfer $S$ that implements it can be calculated as the expected discounted value of future revenues the firm would lose if the process $x_{t}$ cannot exceed (is reflected to) $x_{\tau}$ once that it is reached.

For a given barrier $a$, a reflected process is a process that has the same dynamics as the original one but it is required to stay below $a$ whenever the original process tends to exceed it. Denoting with $\tilde{x}_{t}$ the reflected process, it can be represented as (Harrison, 2013):

$$
\tilde{x}_{t} \equiv x_{t} / D_{t}, \text { for } \quad \tilde{x}_{t} \in(0, a]
$$

where:

(i) $x_{t}$ is a geometric Brownian motion, with stochastic differential as in (1);

(ii) $D_{t}$ is an increasing and continuous process, with $D_{0}=1$ if $x_{0} \leq a$, and $D_{0}=x_{0} / a$ if $x_{0}>a$, so that $\tilde{x}_{0}=a$;

(iii) $D_{t}$ increases only when $\tilde{x}_{t}=a$.

By applying Ito's lemma to (C.1), we get:

$$
d \tilde{x}_{t}=\sigma \tilde{x}_{t} d z_{t}-d \tilde{D}_{t}, \tilde{x}_{t} \in(0, a]
$$

where $d \tilde{D}_{t}=\tilde{x}_{t} \frac{d D_{t}}{D_{t}}$ indicates the infinitesimally small level of "regulation" exerted to let $x_{t}$ stay at $a$. By (C.2), until $x_{t}$ hits for the first time $a$ the two processes coincide, that is, $\tilde{x}_{t}=x_{t}$, and after that, we get $\tilde{x}_{t}<x_{t}$. Specifically, when $\tilde{x}_{t}=a$, we get $d \tilde{x}_{t}=0$ and the rate of variation of $D_{t}$ is equal to the one required to keep $\tilde{x}_{t}$ constant.

Now, defining the difference $\tilde{x}_{t}-x_{t} \equiv U_{t}=\left(D_{t}-1\right) x_{t}$ as the cumulative amount of revenues lost up to $t$ to keep the process below $a$, we are able to calculate the expected future values of revenues evaluated at the process reflected at $a$. In the specific, generalizing for any arbitrary initial value $x_{t}, t>0$, we get:

$$
v\left(x_{t}, a\right)=E_{t}\left\{\int_{t}^{\infty} e^{-r(s-t)}\left[\left(\tilde{x}_{s}-c\right) d s+\rho d U_{s}\right]\right\}
$$

where $\rho>0$ is the marginal reflection cost (i.e., the value attributed to each unit of revenues) and $d U_{s}$ is the reduction of revenues, if any, in the interval $(s, s+d s)$. For all $x_{t}<a$, the function $v\left(x_{t} ; a\right)$ is the unique solution of the following partial differential equation:

$$
\frac{1}{2} \sigma^{2} x_{t}^{2} \frac{\partial^{2} v\left(x_{t}, a\right)}{\partial x_{t}^{2}}-r v\left(x_{t}, a\right)+\frac{x_{t}}{r}=0
$$


with the boundary conditions:

$$
\left.\frac{\partial v\left(x_{t}, a\right)}{\partial x_{t}}\right|_{x_{t}=a}=\rho
$$

The general solution of (C.4) is:

$$
v\left(x_{t}, a\right)=\frac{x_{t}-c}{r}+A x_{t}^{\beta_{1}}
$$

where $A$ is a constant to be determined.

Imposing the boundary condition (C.5), it is easy to show that:

$$
A=\frac{a}{\beta_{1} r}[r \rho-1] a^{-\beta_{1}}
$$

which is negative if $\rho<1 / r$.

By (C.6) and (C.7) the expected discounted value of lost revenues is given by:

$$
A x_{t}^{\beta_{1}}=E_{t}\{\int_{t}^{\infty} \overbrace{}^{-r(s-t)}\left[\varrho d U_{s}\right]\}=\left(\frac{x_{t}}{a}\right)^{\beta_{1}} \frac{a}{\beta_{1}}\left[\rho-\frac{1}{r}\right]
$$

Setting $a=x_{\tau}$ and the reflection cost equals to the marginal value of the exit option evaluated at $a=x_{\tau}$, that is, $\rho=-\frac{\partial O}{\partial x}\left(x_{\tau}\right)=\frac{1}{r}\left(\frac{x_{\tau}}{x^{E}}\right)^{\beta_{2}-1}$, we get:

$$
v\left(x_{t}, x_{\tau}\right)=\frac{x_{t}-c}{r}-\left(\frac{x_{t}}{x_{\tau}}\right)^{\beta_{1}} \frac{x_{\tau}}{\beta_{1} r}\left[1-\left(\frac{x_{\tau}}{x^{E}}\right)^{\beta_{2}-1}\right]
$$

where we express $\rho$ in term of present value, that is, the reflection cost has the dimension of the present value of the marginal cost of one unit of revenues lost forever. Notice that the second term on the RHS of (C.9) is indeed the value to invest given by Equation (B.3).

\section{Second step}

Finally, direct inspection of Equation (B.4) and (C.9) shows that, provided that $v\left(x_{t}, x_{\tau}\right)<I-O\left(x_{t}\right)$, a transfer $S\left(x_{\tau}\right)=\left(I-O\left(x_{t}\right)-v\left(x_{t}, x_{\tau}\right)\right.$ compensates the firm at each time $t$ for the value loss due to the reflecting barrier, that is, $u\left(x_{t}, x_{\tau}\right)-S\left(x_{\tau}\right)>0$. When $x_{t}=x_{\tau}$, we get $u\left(x_{\tau}, x_{\tau}\right)-S\left(x_{\tau}\right)=0$, that is, the firm is indifferent between investing or postponing the decision. Hence, the transfer is:

$$
S\left(x_{\tau}\right)=\left(I-O\left(x_{\tau}\right)\right)-v\left(x_{\tau}, x_{\tau}\right)=I+\frac{c}{r}-\frac{\beta_{1}-1}{\beta_{1}} \frac{x_{\tau}}{r}-\frac{\beta_{1}-\beta_{2}}{\beta_{1}} O\left(x_{\tau}\right)
$$

\section{APPENDIX D: PROOF OF PROPOSITION 1}

For every initial value $x$ there exists a nonincreasing function $\tau(x)=\inf \left(t>0 / x_{t}=x_{\tau}(x)\right)$ which solves the government's optimization problem (15). Further, the allocation mechanism $\tau(x)$ can be implemented by using simple transfers that only depend on the initial value $x$ and the actual time of investment. Specifically, along with the condition (B.5), with $u(x)=u\left(x, x_{\tau}(x)\right)$, an incentive-compatible contract requires the monotonicity of the optimal investment trigger, that is:

$$
\frac{d x_{\tau}(x)}{d x}<0
$$

Conditions (B.5) and (D.1) are the first- and second-order incentive-compatibility constraints to induce the firm to reveal her type $x$. 
The standard approach is to ignore, for the moment, the monotonicity constraint (D.1) and to solve the relaxed problem. For any choice of $x_{\tau}=x_{\tau}(\hat{x})$, by applying the Envelope Theorem where the firm maximizes over both the report $\hat{x}$ and the investment time $x_{\tau}(\hat{x})$, we get the ex-ante project's private value:

$$
u(x)-u\left(x_{l}\right)=-\int_{x_{l}}^{x_{\ngtr}} \frac{1}{r}\left(\frac{y}{x_{\tau}}\right)^{\beta_{1}-1}\left[1-\left(\frac{x_{\tau}}{x^{E}}\right)^{\beta_{2}-1}\right] d y \quad F(x)=F\left(x_{l}, x_{\tau}\left(x_{l}\right)\right)+\int_{x_{l}}^{x_{\ngtr}} \frac{1}{r}\left(\frac{y}{x_{\tau}}\right)^{\beta_{1}-1}\left[1-\left(\frac{x_{\tau}}{x^{E}}\right)^{\beta_{2}-1}\right] d y
$$

where by the Revelation Principle, the optimal choice of $\hat{x}$ is $x$. Since $F(x)$ is increasing in $x$, it is optimal for the government to set the transfer in such a way so that the value of the lowest type is zero, that is, $F\left(x_{l}, x_{\tau}\left(x_{l}\right)\right)=0$. Substituting (D.2) into Equation (14), the government's objective function becomes:

$$
\mathscr{R}\left(x, x_{\tau}\right)=\int_{x_{l}}^{x_{h}}\left[W\left(x, x_{\tau}\right)-\frac{1}{r} \int_{x_{l}}^{x}\left(\frac{y}{x_{\tau}}\right)^{\beta_{1}-1}\left(1-\left(\frac{x_{\tau}}{x^{E}}\right)^{\beta_{2}-1}\right) d y\right] g(x) d x
$$

Integrating by parts the second term on RHS of (D.3) yields:

$$
\int_{x_{l}}^{x_{h}} \uparrow \int_{x_{l}}^{\mathrm{x}}\left\{\left(\frac{y}{x_{\tau}}\right)^{\beta_{1}-1}\left(1-\left(\frac{x_{\tau}}{x^{E}}\right)^{\beta_{2}-1}\right) d y g(x) d x=\int_{x_{l}}^{x_{h}}+\left(\frac{x}{x_{\tau}}\right)^{\beta_{1}-1}\left(1-\left(\frac{x_{\tau}}{x^{E}}\right)^{\beta_{2}-1}\right)(1-G(x)) d x\right.
$$

Substituting (D.4) into (D.3), the government's revenue $\mathscr{R}\left(x, x_{\tau}\right)$ reduces to:

$$
\begin{aligned}
\mathscr{R}\left(x, x_{\tau}\right) & =\int_{x_{l}}^{x_{h}}\left[W\left(x, x_{\tau}\right)-\frac{1}{r}\left(\frac{x}{x_{\tau}}\right)^{\beta_{1}-1}\left(1-\left(\frac{x_{\tau}}{x^{E}}\right)^{\beta_{2}-1}\right) \frac{(1-G(x))}{g(x)}\right] g(x) d x \\
& =\int_{x_{l}}^{x_{h}}\left[W\left(x, x_{\tau}\right)-\frac{(1-G(x))}{g(x)} F_{x}\left(x, x_{\tau}\right)\right] g(x) d x=\int_{x_{l}}^{x_{h}} \hat{W}\left(x, x_{\tau}(x) g(x) d x\right.
\end{aligned}
$$

where $\hat{W}\left(x, x_{\tau}(x) \equiv W\left(x, x_{\tau}(x)\right)-\frac{1-G(x)}{g(x)} F_{x}\left(x, x_{\tau}(x)\right)\right.$ is the "virtual welfare." By substituting the expression for $W\left(x, x_{\tau}\right)$ we get:

$$
\mathscr{R}\left(x, x_{\tau}\right)=\int_{x_{l}}^{x_{h}}\left(\frac{x}{x_{\tau}}\right)^{\beta_{1}}\left\{\frac{x_{\tau}}{r}\left[1-\left(1-\left(\frac{x_{\tau}}{x^{E}}\right)^{\beta_{2}-1}\right) \phi(x)\right]-\left(I+\frac{c}{r}-\frac{b}{r}\right)\right\} g(x) d x
$$

where $\phi(x)=\frac{1-G(x)}{g(x) x}$, with $\phi^{\prime}(x)<0, \phi\left(x^{h}\right)=0$ and $\phi\left(x^{l}\right)=\frac{1}{g\left(x^{l}\right) x^{l}}<1$.

Equation (D.5) can be optimized pointwise for each possible initial value $x$, leading to:

$$
x_{\tau^{W}}-x_{\tau}(1-\phi(x))-\frac{\left(\beta_{1}-\beta_{2}\right)}{\left(\beta_{1}-1\right)}\left(\frac{x_{\tau}}{x^{E}}\right)^{\beta_{2}-1} x_{\tau} \phi(x)=0
$$

from which we obtain the expression of $x_{\tau}(x)$ in the text, with $x_{\tau}\left(x^{h}\right)=x_{\tau^{W}}$.

Equation (D.6) may admit two solutions. Let's define $f\left(x_{\tau}, x_{\tau^{W}}\right) \equiv x_{\tau^{W}}-(1-\phi(x)) x_{\tau}-\left(\frac{\beta_{1}-\beta_{2}}{\beta_{1}-1}\right)\left(\frac{x_{\tau}}{x^{E}}\right)^{\beta_{2}} x^{E} \phi(x)$. It is easy to show that $f\left(x_{\tau}, x_{\tau^{W}}\right)$ is concave in $x_{\tau}$, that is:

$$
f^{\prime}\left(x_{\tau}, x_{\tau^{w}}\right)=-(1-\phi(x))+\left(\beta_{1}-\beta_{2}\right)\left(\frac{x_{\tau}}{x^{E}}\right)^{\beta_{2}-1} \phi(x)
$$

and 


$$
f^{\prime \prime}\left(x_{\tau}, x_{\tau^{W}}\right)=\left(\beta_{1}-\beta_{2}\right)\left(\beta_{2}-1\right)\left(\frac{x_{\tau}}{x^{E}}\right)^{\beta_{2}-2} \frac{1}{x^{E}} \phi(x)<0
$$

Moreover, since $\lim _{x_{\tau} \rightarrow \infty} f\left(x_{\tau}, x_{\tau^{W}}\right)=-\infty$ and $\lim _{x_{\tau} \rightarrow 0} f\left(x_{\tau}, x_{\tau^{w}}\right)=-\infty$, the maximum is given by:

$$
\left(\beta_{1}-\beta_{2}\right)\left(\frac{x_{\tau}^{\max }}{x^{E}}\right)^{\beta_{2}-1} \frac{\phi(x)}{1-\phi(x)}=1
$$

Substituting $x_{\tau}^{\max }$ into $f\left(x_{\tau}, x_{\tau^{W}}\right)$ we get:

$$
f\left(x_{\tau}^{\max }, x_{\tau^{W}}\right)=x_{\tau^{W}}-\left(\beta_{1}-\beta_{2}\right)\left(\frac{x_{\tau}^{\max }}{x^{E}}\right)^{\beta_{2}} x^{E} \phi(x)\left(\frac{\beta_{1}}{\beta_{1}-1}\right)
$$

Hence, if $f\left(x_{\tau}^{\max }, x_{\tau^{w}}\right)>0$, the first-order condition (D.6) admits two solutions and the optimal one satisfies $x_{\tau}>x_{\tau}^{\max }$.

Let's now prove the monotonicity. By totally differentiating (D.6), we obtain:

$$
\frac{d x_{\tau}}{d x}\left[(1-\phi(x))-\left(\beta_{1}-\beta_{2}\right)\left(\frac{x_{\tau}}{x^{E}}\right)^{\beta_{2}-1} \phi(x)\right]=x_{\tau} \phi^{\prime}(x)\left[1-\frac{\left(\beta_{1}-\beta_{2}\right)}{\left(\beta_{1}-1\right)}\left(\frac{x_{\tau}}{x^{E}}\right)^{\beta_{2}-1}\right]
$$

Defining $\Omega\left(x_{\tau}\right) \equiv \frac{\left(\beta_{1}-\beta_{2}\right)}{\left(\beta_{1}-1\right)}\left(\frac{x_{\tau}}{x^{E}}\right)^{\beta_{2}-1}$, it is easy to show that $\frac{d x_{\tau}}{d x}<0$ if:

$$
\Omega\left(x_{\tau}\right)<\frac{1}{\beta_{1}-1} \frac{1-\phi(x)}{\phi(x)}=\frac{1}{\beta_{1}-1} \frac{\left(x-\frac{1-G(x)}{g(x)}\right)}{\frac{1-G(x)}{g(x)}}
$$

and

$$
\Omega\left(x_{\tau}\right)<1
$$

hold simultaneously, where (D.8.1) is the second-order condition of the maximization, while (D.8.2) implies $x_{\tau}>x_{\tau^{W}}$, that is:

$$
1-\Omega\left(x_{\tau}\right)=\left[1-\frac{\left(\beta_{1}-\beta_{2}\right)}{\left(\beta_{1}-1\right)}\left(\frac{x_{\tau}}{x^{E}}\right)^{\beta_{2}-1}\right]=\left[\frac{1}{\phi(x)}-\frac{1}{x_{\tau} \phi(x)} \frac{\beta_{1}}{\left(\beta_{1}-1\right)} r\left(I+\frac{c}{r}-\frac{b}{r}\right)\right]=\frac{1}{\phi(x)} \frac{1}{x_{\tau}}\left[x_{\tau}-x_{\tau^{W}}\right]
$$

Since $\frac{1-\phi(x)}{\phi(x)}$ is increasing in $x$, a sufficient condition for the second-order condition (D.8.1) to hold is $\Omega\left(x_{\tau}\right)<\frac{g\left(x^{l}\right) x^{l}-1}{\beta_{1}-1}$. Thus, we need to distinguish two cases:

- If $g\left(x^{l}\right) x^{l} \in\left(1, \beta_{1}\right]$, then (D.8.2) is satisfied if and only if (D.8.1) is also satisfied;

- If $g\left(x^{l}\right) x^{l}>\beta_{1}$, then (D.8.1) is satisfied if and only if (D.8.2) is also satisfied.

Let's consider the first case where $g\left(x^{l}\right) x^{l} \in\left(1, \beta_{1}\right]$. This implies that $\frac{g\left(x^{l}\right) x^{l}-1}{\beta_{1}-1}<1$ and, since $x_{\tau}\left(x^{h}\right)=x_{\tau^{W}}$, we can reduce (D.8.1) to:

$$
\left(\frac{x^{E}}{x_{\tau^{W}}}\right)<K \frac{g\left(x^{l}\right) x^{l}-1}{\beta_{1}-1}
$$

where $K=\left(\frac{\beta_{1}-1}{\beta_{1}-\beta_{2}}\right)^{1 / 1-\beta_{2}}<1$.

As for the second case, we get $\frac{g\left(x^{l}\right) x^{l}-1}{\beta_{1}-1}>1$. Thus, condition (D.8.2) is satisfied by simply setting $\left(\frac{x^{E}}{x_{\tau} W}\right)<K$. Therefore, Assumptions 1 guarantees that both (D.8.1) and (D.8.2) are satisfied. 
Suppose now that $\frac{x^{E}}{x_{\tau} W}$ is such that Assumption 1 is not satisfied. Hence, for higher values of $x$, conditions (D.8.1) and (D.8.2) may not hold. In this case we have an interval $\left[x^{\prime}, x^{\prime \prime}\right] \subset\left[x^{l}, x^{h}\right]$ where a constant trigger (bunching) applies such that $x_{\tau}\left(x^{\prime}\right)=x_{\tau}\left(x^{\prime \prime}\right)=\bar{x}_{\tau}>x_{\tau}\left(x^{h}\right)=x_{\tau^{w}}$. Thus, from (D.7), we should have $\phi^{\prime}\left(x^{\prime}\right)=\phi^{\prime}\left(x^{\prime \prime}\right)$ and from (D.6):

$$
\begin{aligned}
-\left(1-\phi\left(x^{\prime}\right)\right) \bar{x}_{\tau}-\left(\frac{\beta_{1}-\beta_{2}}{\beta_{1}-1}\right)\left(\frac{\bar{x}_{\tau}}{x^{E}}\right)^{\beta_{2}} x^{E} \phi\left(x^{\prime}\right)= & -\left(1-\phi\left(x^{\prime \prime}\right)\right) \bar{x}_{\tau}-\left(\frac{\beta_{1}-\beta_{2}}{\beta_{1}-1}\right)\left(\frac{\bar{x}_{\tau}}{x^{E}}\right)^{\beta_{2}} x^{E} \phi\left(x^{\prime \prime}\right)\left(\phi\left(x^{\prime}\right)\right. \\
& \left.-\phi\left(x^{\prime \prime}\right)\right)\left[1-\left(\frac{\beta_{1}-\beta_{2}}{\beta_{1}-1}\right)\left(\frac{\bar{x}_{\tau}}{x^{E}}\right)^{\beta_{2}-1}\right] \bar{x}_{\tau} \\
= & 0\left(\phi\left(x^{\prime}\right)-\phi\left(x^{\prime \prime}\right)\right)\left[1-\Omega\left(\bar{x}_{\tau}\right)\right] \bar{x}_{\tau}=0
\end{aligned}
$$

This leads to a contradiction as $x^{\prime}>x^{\prime \prime}$ and $1-\Omega\left(\bar{x}_{\tau}\right) \neq 0$ except when $\bar{x}_{\tau}=x_{\tau^{w}}$. Thus, we cannot have $x^{\prime \prime}<x^{h}$ and if bunching is optimal it occurs at the top of the interval. However since there is no distortion at the top, the optimal solution is $x_{\tau}\left(x^{h}\right)=x_{\tau^{w}}$ for an interval $\left[\hat{x}, x^{h}\right] \subset\left[x^{l}, x^{h}\right]$ for some $\hat{x}$.

The public transfer is given by Lemma 1. By substituting (D.6) into (C.10):

$$
\begin{aligned}
S\left(x_{\tau}\right)= & I+\frac{c}{r}-\frac{\beta_{1}-1}{\beta_{1}} \frac{x_{\tau}}{r}-\frac{\beta_{1}-\beta_{2}}{\beta_{1}} O\left(x_{\tau}, x^{E}\right)=\frac{b}{r}-\frac{\beta_{1}-\beta_{2}}{\beta_{1}} O\left(x_{\tau}, x^{E}\right) \\
& -\frac{\beta_{1}-1}{\beta_{1}}\left[\frac{x_{\tau}^{W}}{r}-\left(\beta_{1}-\beta_{2}\right) O\left(x_{\tau} ; x^{E}\right)\right] \frac{\phi(x)}{1-\phi(x)}
\end{aligned}
$$

with $S\left(x^{h}\right)=\frac{b}{r}-\frac{\beta_{1}-\beta_{2}}{\beta_{1}} O\left(x_{\tau^{W}}, x^{E}\right)=S^{W}$. By the monotonicity of $x_{\tau}$, it is easy to show that:

$$
\frac{\partial S}{\partial x}=-\frac{\beta_{1}-1}{\beta_{1}} \frac{1}{r} \frac{\partial x_{\tau}}{\partial x}+\frac{\beta_{1}-\beta_{2}}{\beta_{1}} \frac{1}{r}\left(\frac{x_{\tau}}{x^{E}}\right)^{\beta_{2}-1} \frac{\partial x_{\tau}}{\partial x}=\frac{1}{\beta_{1} r} \frac{\partial x_{\tau}}{\partial x} \frac{1}{\left(\beta_{1}-1\right)}\left(-1+\frac{\left(\beta_{1}-\beta_{2}\right)}{\left(\beta_{1}-1\right)}\left(\frac{x_{\tau}}{x^{E}}\right)^{\beta_{2}-1}\right)>0
$$

Finally, taking the derivative of (D.6) with respect to $x^{E}$ we get:

$$
\frac{\partial x_{\tau}(x)}{\partial x^{E}}=-\frac{\left(\beta_{2}-1\right) \frac{\left(\beta_{1}-\beta_{2}\right)}{\left(\beta_{1}-1\right)}\left(\frac{x_{\tau}}{x^{E}}\right)^{\beta_{2}} \phi(x)}{S O C}<0
$$

where the second-order condition is satisfied by Assumptions 1, and the derivative of (D.10) gives:

$$
\frac{\partial S}{\partial x^{E}}=\frac{\left(\beta_{1}-\beta_{2}\right)}{\beta_{1}} \frac{\partial O\left(x_{\tau}, x^{E}\right)}{\partial x^{E}}\left[\frac{\phi(x)}{1-\phi(x)}\left(\beta_{1}-1\right)-1\right]
$$

which is negative for all $x$ if $g\left(x^{l}\right) x^{l}>\beta_{1}$. Otherwise $\frac{\partial S}{\partial x^{E}}>0$ for low values of $x$ and $\frac{\partial S}{\partial x^{E}}<0$ for high values of $x$ if $1<g\left(x^{l}\right) x^{l}<\beta_{1}$.

\section{APPENDIX E: PROOF OF PROPOSITION 2}

Recalling that $\hat{W}\left(x, x_{\tau}\right)$ is the "virtual welfare," the sign of $\frac{\partial \mathscr{R}}{\partial L}$ is given by:

$$
\frac{\partial \mathscr{R}}{\partial L}=\int_{x_{l}}^{x_{h}}\left[\frac{\partial \hat{W}\left(x, x_{\tau}\right)}{\partial x_{\tau}} \frac{\partial x_{\tau}}{\partial L}+\frac{\partial \hat{W}\left(x, x_{\tau}\right)}{\partial L}\right] g(x) d x .
$$

Since $x_{\tau}$ is the optimum, the first term is equal to zero. Thus, the derivative simplifies to: 


$$
\frac{\partial \mathscr{R}}{\partial L}=\int_{x_{l}}^{x_{h}}\left[-\frac{1-G(x)}{g(x)} \frac{\partial F_{x}\left(x, x_{\tau}\right)}{\partial L}\right] g(x) d x .=\int_{x_{l}}^{x_{h}}\left\{-\frac{1-G(x)}{g(x)}\left(\frac{x}{x_{\tau}}\right)^{\beta_{1}-1} \frac{1}{r}\left[\left(\beta_{2}-1\right)\left(\frac{x_{\tau}}{x^{E}}\right)^{\beta_{2}} \frac{1}{x_{\tau}} \frac{\partial x^{E}}{\partial L}\right]\right\} g(x) d x<0
$$

which is always negative.

To study the effect of a change of $L$ on $\mathscr{R}$, we can substitute (D.6) into (D.5) and rewrite the virtual welfare as follows:

$$
\begin{aligned}
\hat{W}\left(x, x_{\tau}\right)= & (1-\phi(x))\left(\frac{x}{x_{\tau}}\right)^{\beta_{1}} \frac{x_{\tau}}{\beta_{1} r}\left(1-\left(\frac{x_{\tau}}{x^{E}}\right)^{\beta_{2}-1}\right)+\left[1-\beta_{1} \phi(x)\right]\left(\frac{x}{x_{\tau}}\right)^{\beta_{1}} \frac{x_{\tau}}{\beta_{1} r}\left(\frac{x_{\tau}}{x^{E}}\right)^{\beta_{2}-1}=(1-\phi(x)) F\left(x, x_{\tau}\right) \\
& +\hat{O}\left(x, x_{\tau}\right)
\end{aligned}
$$

Recalling that $F\left(x, x_{\tau}\right)=\left(\frac{x}{x_{\tau}}\right)^{\beta_{1}} \frac{x_{\tau}}{\beta_{1} r}\left(1-\left(\frac{x_{\tau}}{x^{E}}\right)^{\beta_{2}-1}\right), F_{x}\left(x, x_{\tau}\right)=\frac{1}{r}\left(\frac{x}{x_{\tau}}\right)^{\beta_{1}-1}\left(1-\left(\frac{x_{\tau}}{x^{E}}\right)^{\beta_{2}-1}\right)$ and $\phi(x)=\frac{(1-G(x))}{g(x) x}$, the first term on the RHS of (E.3) is the standard "virtual value," that is, the expected surplus extracted from a firm of type $x$ as long as she remains operational:

$$
(1-\phi(x)) F\left(x, x_{\tau}\right)=F\left(x, x_{\tau}\right)-\frac{1-G(x)}{g(x)} \frac{1}{\beta_{1}} F_{x}\left(x, x_{\tau}\right)
$$

On the other hand, recalling that $O\left(x_{\tau}\right)=-\left(\frac{x_{\tau}}{x^{E}}\right)^{\beta_{2}} \frac{x^{E}}{\beta_{2} r}$ represents the value assigned by the firm to the exit option at the time of investment, the second term on the RHS of (E.3) measures what the government expects to earn by granting an exit option:

$$
\hat{O}\left(x, x_{\tau}\right)=-\left[1-\beta_{1} \phi(x)\right]\left(\frac{x}{x_{\tau}}\right)^{\beta_{1}} \frac{\beta_{2}}{\beta_{1}} O\left(x_{\tau}\right)
$$

Finally, since the expected discount factor is $E_{0}\left(e^{-r \tau}\right)=\left(\frac{x}{x_{\tau}}\right)^{\beta_{1}}$, Equation (E.3) reduces to:

$$
\begin{aligned}
\hat{W}\left(x, x_{\tau}\right)= & E_{0}\left(e^{-r \tau}\right)\left\{[\underbrace{\frac{x_{\tau}}{\beta_{1} r}\left(1-\left(\frac{x_{\tau}}{x^{E}}\right)^{\beta_{2}-1}\right)}_{\text {NPV at the moment of investment }}-\underbrace{\phi(x) \frac{x_{\tau}}{\beta_{1} r}\left(1-\left(\frac{x_{\tau}}{x^{E}}\right)^{\beta_{2}-1}\right)}_{\text {Information rents }}\right. \\
& +\underbrace{\left.\left.\left(1-\beta_{1} \phi(x)\right) \frac{x_{\tau}}{\beta_{1} r}\left(\frac{x_{\tau}}{x^{E}}\right)^{\beta_{2}-1}\right]\right\}}_{\text {Option premium }}
\end{aligned}
$$

By totally differentiating (E.6) with respect to the exit fee, we are able to decompose the effect of a change of $L$ into four components:

$$
\begin{aligned}
\frac{\partial \hat{W}}{\partial L}= & \frac{\partial E_{0}\left(e^{-r \tau}\right)}{\partial L}\{\ldots\}+E_{0}\left(e^{-r \tau}\right)\left\{\frac{\partial N P V}{\partial L}-\frac{\partial \text { Rents }}{\partial L}+\frac{\partial \text { Option }}{\partial L}\right\}=\left(1-\beta_{1}\right) \frac{\hat{W}}{x_{\tau}} \frac{\partial x_{\tau}}{\partial x^{E}} \frac{\partial x^{E}}{\partial L} \\
& +F\left(x, x_{\tau}\right)\left(1-\beta_{2}\right) \frac{\left(\frac{x_{\tau}}{x^{E}}\right)^{\beta_{2}-1}}{\left(1-\left(\frac{x_{\tau}}{x^{E}}\right)^{\beta_{2}-1}\right)}\left(\frac{1}{x_{\tau}} \frac{\partial x_{\tau}}{\partial x^{E}}-\frac{1}{x^{E}}\right) \frac{\partial x^{E}}{\partial L}-\phi(x) F\left(x, x_{\tau}\right)\left(1-\beta_{2}\right) \frac{\left(\frac{x_{\tau}}{x^{E}}\right)^{\beta_{2}-1}}{\left(1-\left(\frac{x_{\tau}}{x^{E}}\right)^{\beta_{2}-1}\right)}\left(\frac{1}{x_{\tau}} \frac{\partial x_{\tau}}{\partial x^{E}}\right. \\
& \left.-\frac{1}{x^{E}}\right) \frac{\partial x^{E}}{\partial L}+\left(1-\beta_{2}\right) \hat{O}\left(x_{\tau}\right)\left(\frac{1}{x_{\tau}} \frac{\partial x_{\tau}}{\partial x^{E}}-\frac{1}{x^{E}(L)}\right) \frac{\partial x^{E}}{\partial L}
\end{aligned}
$$


The sign of the first term on the RHS of (E.7) is negative and represents the overall effect of the discount rate on the virtual welfare. The sign of the second term is positive and measures the effect on the project's NPV. The third term measures the effect on the information rents and it is negative. Finally, the last term, which measures the effect on the option premium, is negative if $\left(1-\beta_{1} \phi(x)\right)>0$, and positive otherwise.

\section{APPENDIX F: ADDITIONAL RESUMPTION COSTS}

In the main text we have assumed that the government will resume the project by incurring the same cash flows that would have been incurred by the firm, which implies that negative project's market value will simply give the resumption cost. Here we extend our analysis to the case where the government has to afford additional costs beyond those the firm herself would have incurred absent the termination.

Suppose that the government needs to afford an additional (one-time, sunk) $\operatorname{cost} Z \geq 0$. In this case, Equation (D.5) becomes:

$$
\mathscr{R}\left(x, x_{\tau}\right)=\int_{x_{l}}^{x_{h}}\left\{\hat{W}\left(x, x_{\tau}\right)-E_{0}\left(e^{-r T}\right) Z\right\} g(x) d x
$$

Since $E_{0}\left(e^{-r T}\right)=\left(\frac{x}{x^{E}}\right)^{\beta_{2}}$, the derivative of (F.1) with respect to $L$ becomes:

$$
\begin{aligned}
\frac{\partial \mathscr{R}}{\partial L} & =\int_{x_{l}}^{x_{h}}\left\{-\frac{1-G(x)}{g(x)}\left(\frac{x}{x_{\tau}}\right)^{\beta_{1}-1} \frac{1}{r}\left[\left(\beta_{2}-1\right)\left(\frac{x_{\tau}}{x^{E}}\right)^{\beta_{2}} \frac{1}{x_{\tau}} \frac{\partial x^{E}}{\partial L}\right]-\beta_{2}\left(\frac{x}{x^{E}}\right)^{\beta_{2}} \frac{r Z}{(c-r L)}\right\} g(x) d x \\
& =\beta_{2} \int_{x_{l}}^{x_{h}}\left(\frac{x_{\tau}}{x^{E}}\right)^{\beta_{2}}\left[\left(\frac{x}{x_{\tau}}\right)^{\beta_{1}} \phi(x)-\left(\frac{x}{x_{\tau}}\right)^{\beta_{2}} \frac{r Z}{(c-r L)}\right] g(x) d x
\end{aligned}
$$

The first term inside the squared brakets is negative while the second is positive. If $Z \rightarrow 0$ we get $\frac{\partial \mathscr{R}}{\partial L}<0$, while if $Z$ increases it may happen that $\frac{\partial \mathscr{R}}{\partial L}>0$ with consequent result that it is optimal to set $L=\frac{c}{r}$. More generally, since $\mathscr{R}$ is a continuous function on the closed interval $\left[0, \frac{c}{r}\right]$ and is differentiable on the open interval $\left(0, \frac{c}{r}\right)$, the net revenue $\mathscr{R}$ is U-shaped and admits a minimum in the range $\left(0, \frac{c}{r}\right)$ with $L^{\min }=0$ if $Z=0$. Besides, by the Mean Value Theorem, for any given $Z$, there exists a value of $\hat{L}(Z) \in\left(0, \frac{c}{r}\right)$ such that:

$$
\mathcal{R}\left(L=\frac{c}{r}\right)-\mathcal{R}(L=0)=\mathcal{R}^{\prime}(\hat{L}(Z)) \frac{c}{r}
$$

where $\mathcal{R}\left(\frac{c}{r}\right)$ and $\mathcal{R}(0)$ represent the government's revenue with $L=\frac{c}{r}$ and with $L=0$, respectively.

Therefore, we can conclude that the government will still maximize his own expected revenue by maximizing the value of the exit option, that is, by setting $L=0$, if the additional costs $Z$ are not too high relative to the net benefits arising from allowing the firm to quit without any fee attached, that is, if $\mathcal{R}^{\prime}(\hat{L}(Z))<0$. 